\title{
Formulation and Solution of the Delayed Gamma Dose Rate Problem Using the Concept of Effective Delayed Gamma Production Cross Sectioi
}

\author{
S. L. Liew and L. P. Ku \\ Princeton Plasma Physics Laboratory \\ Princeton Liniversity \\ Princeton, New Jersey 08543
}

\begin{abstract}
With appropriate approximations, the delayed gamma dose rate problem can be formulated in terms of the effective delayed gamma production cross section. The coupled neutron-delayed-gamma transport equations then take the same form as the coupled neutronprompt-ganma transport equations and they can, therefore, be solved directly in the same manner. This eliminates the need for the tedious and error prone flux coupling step in conventional calculations. Mathematical formulation and solution algorithms are derived. The advantages of this method are illustrated by an example of its application in the solution of a practical design problem.
\end{abstract}

\section{DISCLAIMER}

This report was prepared as an scoount of wark sponsored by an egency of the United Slates Government. Neither tbe United Stutea Government nor any ageacy tbereof, nor any of their employees, makes any werranty, express or implied, or exsumes any lezal liability or responsibility for the ecuracy, completeness or usefulaces of any information, apperalus, product, of process disclesed, or represents that its use would oot infriege privately owood rights. Referente herein to any specific commercial product, process, of service by trade name, trademurk, manufacturet, or obberwise does not necesurily constitute or imply its endorsenteat, recommendation, or faworing by the Uniled States Goweramept or any asency thereof. The views and opinions of authors expresued bertin do not nocesurily state or reflect those of the United States Government or any ageocy tbeteof. 


\section{Introduction}

In any facility where neutrons are being produced in significant numbers, a commonly encountered problem is the health hazards due to the neutron-induced activation of materials. The potential biological dose rates due to the delayed $\gamma$-rays emitted by the activated nuclides are often so high at some locations as to require remote maintenance capability or large amounts of shielding for hands-on maintenance. To assess the problems posed by the activated materials and to design properly the required shielding, it is necessary to calculate the dose rates at various locations as functions of neutron irradiation history. ${ }^{1-9}$

In general, this requires a solution of the time-dependent coupled neutron-gamma transport equations. The problem is intractable on present generation computers without appropriate approximations. A frequently used approximation for treating the time dependence is that the flux distribution is independent of time within a time interval $\delta t$ so that only a 'quasi-static' transport equation is solved within each time step, which may involve further approximations on the energy, spatial, and angular variables ${ }^{10-16}$ to render the solution feasible. To minimize the computation time, the quasi-static equation is updated only after a number of time steps.

Very often, practical constraints require that the quasi-static approximation be made for large $\delta t$, or even the entire time domain of interest. Numerous examples of delayed- $\gamma$ dose rate calculations based on this assumption can be found in the literature. ${ }^{1-7}$

These calculations typically require a flux coupling procedure in the activation calculations, which makes it very difficult and error prone when complicated systems are analyzed. In this paper, we demonstrate that the flux coupling problems can be eliminated by adopting a new approach based on the concept of effective delaved- $\gamma$ production cross section. The method is particularly suitable for dealing with complici ted geometries where the flux coupling problems become most pronounced.

\section{Theoretical Formulation of the Delayed Gamma Dose Rate Problem}

The delayed $\gamma$ dose tate problem may be stated as follows:

Given a system with a time-dependent neutron source $Q_{n}\left(\vec{r}, E_{n}, \vec{\Omega}, t\right)$, and some boundary and initial conditions, find the delayed $\gamma$ dose rate distribution $D\left(\vec{r}, t^{\prime}\right)$, where $t^{\prime} \geq t$.

Within the framework of classical transport theory, this generally requires the solution of the coupled neutron-gamma transport equations (see the Appendix for definitions of the notations):

$$
\frac{1}{v} \frac{\partial}{\partial t} \Phi_{n}\left(\vec{r}, E_{n}, \vec{\Omega}, t\right) \div \mathcal{L}_{r} \Phi_{n}\left(\vec{r}, E_{n}, \vec{\Omega}, t\right)=Q_{n}\left(\vec{r}, E_{n}, \vec{\Omega}, t\right)
$$




$$
\frac{1}{c} \frac{\partial}{\partial t^{\prime}} \Phi_{r}\left(\vec{r}, E_{r}, \vec{\Omega}, t^{\prime}\right)+\mathcal{L}_{r} \Phi_{r}\left(\vec{r}, E_{r}, \vec{\Omega}, t^{\prime}\right)=Q_{\gamma}\left(\vec{r}, E_{r}, \vec{\Omega}, t^{\prime}\right)
$$

for the delayed $\gamma$ flux $\Phi_{\sim}\left(\vec{r}, E_{\gamma}, \vec{\Omega} . t^{\prime}\right)$. subject to the boundary and initial conditions, and foldirg it with the dose response function $R\left(\vec{r}, E_{\checkmark}\right)$ :

$$
D\left(\vec{r}, t^{\prime}\right)=\iint R\left(\vec{r} \cdot E_{\curvearrowright}\right) \Phi_{\sim}\left(\vec{r} . E_{r}, \vec{\Omega} \cdot \iota^{\prime}\right) d E_{\curvearrowright} d \vec{\Omega}
$$

Eqs. (1) and (2) are coupled since the delayed $\gamma$ source $Q_{r}\left(\vec{r}, E_{\gamma}, \vec{\Omega}, t^{\prime}\right)$ depends on the history of the neutron flux, i.e., on $\Phi_{n}\left(\vec{r}, E_{n}, \vec{\Omega} . t\right)$, for all $0 \leq t \leq t^{r}$.

In the absence of feedback and delaved neutrons, the linear Boltzmann transport operators $\boldsymbol{C}_{n}$ and $\boldsymbol{C}_{r}$ take the forms:

$$
\begin{gathered}
C_{n} \Phi_{n}\left(\vec{r}, E_{n,} \vec{\Omega}, t\right)=\Sigma_{T, n}\left(\vec{r}, E_{n}\right) \Phi_{n}\left(\vec{r}, E_{n+} \vec{\Omega}, t\right) \\
-\iint \Phi_{n}\left(\vec{r}, E_{n}^{\prime}, \vec{\Omega}^{\prime}, t\right) \Sigma_{s, n}\left(\vec{r}, E_{n}^{\prime} \rightarrow E_{n}, \vec{\Omega}^{\prime} \rightarrow \vec{\Omega}\right) d E_{n}^{\prime} d \vec{\Omega}^{\prime}
\end{gathered}
$$

and

$$
\begin{gathered}
\mathcal{C}_{\gamma} \Phi_{\gamma}\left(\vec{r}, E_{r}, \vec{\Omega}, t^{\prime}\right)=\Sigma_{T_{, \gamma}}\left(\vec{r}, E_{\gamma}\right) \Phi_{\gamma}\left(\vec{r}, E_{r i} \vec{\Omega}, t^{\prime}\right) \\
\div \iint \Phi_{\gamma}\left(\vec{r}, E_{\gamma}^{\prime}, \vec{\Omega}^{\prime}, t^{\prime}\right) \Sigma_{g_{\gamma}}\left(\vec{r}, E_{\gamma}^{\prime} \rightarrow E_{\gamma}, \vec{\Omega}^{\prime} \rightarrow \vec{\Omega}\right) d E_{\gamma}^{\prime} d \vec{\Omega}^{\prime} .
\end{gathered}
$$

The delayed $\gamma$ source is given by the decay of the radionuclides:

$$
Q_{\gamma}\left(\vec{r}, E_{\gamma}, \bar{\Omega}, t^{\prime}\right)=\sum_{i=1}^{l} \lambda_{i} N_{i}\left(\vec{r}, t^{\prime}\right) Y_{i}\left(E_{\gamma}, \vec{\Omega}\right)
$$

Under the assumption that the radionuclides are immobile, i.e., they remain at the locations where they are produced, the radionuclide densities $N_{i}(\vec{r}, t)$ are governed by the radioactive decay chain equations:

$$
\begin{gathered}
\frac{\partial N_{i}(\vec{r}, t)}{\partial t}=\iint\left[\sum_{k} N_{k}(\vec{r}, t) \sigma_{k \rightarrow i}\left(\vec{r}, E_{n}\right)-N_{i}(\vec{r}, t) \sigma_{i}^{d}\left(\vec{r}, E_{n}\right)\right] \Phi_{n}\left(\vec{r}, E_{n}, \vec{\Omega}, t\right) d E_{n} d \vec{\Omega} \\
-\lambda_{i} N_{i}(\vec{r}, t)-\sum_{j} \lambda_{j \rightarrow i} N_{j}(\vec{r}, t), \quad i=1, \ldots, I .
\end{gathered}
$$

In principle, Eqs. (1), (2), (6), and ( 7 ) can be solved by discretizing all the variables and integrating them over the required time interval. Unfortunately, this brute force method is beyond the capabilities of present generation computers, unless the transport equations are simplified. 


\section{The Quasi-static Approximation}

The techniques used for obtaining approximate solutions to the space-time dependent transport equations are numerous. ${ }^{17.18}$ Typical simplifying assumptions include the reduction to one ${ }^{\mathrm{i0}}$ or two ${ }^{\mathrm{tI}}$ spatial dimensions. possibly further approximations with the $P_{1}$ or diffusion equation. ${ }^{12,13}$ and ultimately the zero-dimensional approximation. ${ }^{\text {it-16 }}$ Practical limitations require that the treatment of the spatial andjor angular variables be simplified when the time dependence is more important, or vice versa

Since the delayed $\gamma$ problem is often a shielding problem, accuracies in the treatment of the spatial and angular variables are important. especially in the presence of high energy neutron sources. Often, the geometry of the system is so complicated that only a threedimenisional transport model can give any meaningful answer. Hence, solutions are obtained only for highly simplified time-dependence such as steady state, piecewise constant, and delta function sources.

To simplify the treatment of the time variable in complicated geometries, it is often assumed that the time variable is separable a ad the neutron source may be written as the product of a shape function and a time function:

$$
Q_{n}\left(\vec{r}, E_{n}, \vec{\Omega}, t\right)=S_{n}\left(\vec{r}, E_{n}, \vec{\Omega}\right) f(t)
$$

Furthermore, the system is assumed to be quasi-static, i.e., the function $f(t)$ varies on a time scale that is much longer than the neutron lifetime in the system, so that $\frac{1}{v} \frac{\partial}{\partial t} \Phi_{n} \approx 0$ and the transport Eq. (1) reduces to:

$$
C_{n} \Phi_{n}\left(\vec{r}, E_{n}, \vec{\Omega}, t\right)=S_{n}\left(\vec{r}, E_{n}, \vec{\Omega}\right) f(t) .
$$

Since the transport operator $\mathcal{L}_{\mathrm{m}}$ is independent of time in the absence of feedback and delaved neutrons, we have:

$$
\Phi_{n}\left(\vec{r}, E_{n}, \vec{\Omega}, t\right)=\phi_{n}\left(\vec{r}, E_{n}, \vec{\Omega}\right) f(t),
$$

where the neutron flux shape function $\phi_{n}\left(\vec{r}, E_{n}, \vec{\Omega}\right)$ satisfies the time-independent transport equation:

$$
C_{n} \phi_{n}\left(\vec{r}, E_{n}, \bar{\Omega}\right)=S_{n}\left(\vec{r}, E_{n}, \bar{\Omega}\right) .
$$

Also, since the half-lives of the activated nuclides are usually very long compared to the life times of the photons in the system, the delayed $\gamma$ transport Eq. (2) may also be replaced by the quasi-static equation:

$$
\mathcal{C}_{\gamma} \Phi_{\gamma}\left(\vec{r}, E_{r}, \vec{\Omega}, t^{\prime}\right)=Q_{\gamma}\left(\vec{r}, E_{\gamma}, \vec{\Omega}, t^{\prime}\right)=\sum_{i=1}^{I} \lambda_{i} N_{i}\left(\vec{r}, t^{\prime}\right) Y_{i}\left(E_{\gamma}, \vec{\Omega}\right),
$$

where $N_{i}$ satisfies the equations:

$$
\frac{\partial N_{i}(\vec{r}, t)}{\partial t}=f(t) \int\left[\sum_{k} N_{k}(\vec{r}, t) \sigma_{k \rightarrow i}\left(\vec{r}, E_{n}\right)-N_{i}(\vec{r}, t) \sigma_{i}^{d}\left(\vec{r}, E_{n}\right)\right] \varphi_{n}\left(\vec{r}, E_{r}\right) d E_{n}
$$




$$
-\lambda_{i} V_{i}(\vec{r}, t)+\sum_{j} \lambda_{j \rightarrow i} V_{j}(\bar{r}, t), \quad i=1, \ldots, I
$$

$\vec{r}\left(\vec{r}, E_{n}\right)=\int \phi_{n}\left(\vec{r}, E_{n}, \vec{\Omega}\right) d \vec{\Omega}$ being the scaiar neutron flux.

\section{Typical Applications of the Quasi-static Approximation and Practical Difficulties Encountered}

The approximations discussed above have been used frequently in the calculations of the delayed $\gamma$ dose rates in many systems. ${ }^{1-r}$ Typically, these calculations involve the following four steps:

(A) Calculate the neutron flux shape function $\phi_{n}\left(\vec{r}, E_{n}, \vec{\Omega}\right)$ by solving the time-independent neutron transport Eq. (11).

(B) For a particular irradiation scenario and cooling time, the distribution of radionuclides and their delayed $\gamma$ photons are calculated by solving the radioactive decay chain Eqs. (13), and evaluating the expression in Eq. (6). using the neutron flux obtained in step (A) as input. This usually involves coupling the neutron flux solution to an activation code which 'understands' the model in step (A).

(C) Calculate the delayed $\gamma$ flux $\Phi_{\gamma}\left(\vec{r}, E_{r}, \vec{\Omega}, t^{\prime}\right)$ due to the delayed $\gamma$ source distribution by solving Eq. (12), with a transport model that may or may not be the same as the one used in step (A).

(D) Evaluate the integral in Eq. (3) to obtain the dose rates at locations of interest.

Steps (B) - (D) are repeated for as many irradiation histories and cooling times as desired. A commonly used variation on the same theme is to solve the adjoint transport equation in step (C) and convolute the adjoint function with the source distribution obtained in step (B). ${ }^{4}$ This can save computation time when the dose rates are required at many cooling times but only at a small number of locations.

In principle, this method is completely general and is limited only by the modelling capability of the various codes used. This generaliey results in many desirable consequences, such as the following:

In addition to the delayed $\gamma$ distribution, the activation codes used in step (B) can also give the distributions of other quantities of interest such as activity, decay heat, and biological hazard potential. Changes in the geometry after the irradiation can also be handled by corresponding changes in the delayed $\gamma$ transport model. Also, contribution from each isotope in each region can be calculated and examined separately.

The generality also leads to many drawbacks in practice, the most serious ones being the following: 
The activation code used in step (B) usually has an input format and geometry description method which are completely different from those of the transport code used in steps $(A)$ and $(C)$. As a result, the geometrical coupling for a complicated problem becomes very tedious and error prone. The efforts required in setting up the input for the activation calctlations are comparable to those required for the transport solutions. although the computer time required in the former is usually small compared to the latter. This problem becomes more serious when different transport models are used for the neutron and delayed $\gamma$ transport problems. For example. when a deterministic code is used for calculating the neutron distribution, the spatial mesh may need to be made smaller for delayed $\gamma$ transport calculations because of their much smaller mean free paths, thus requiring an additional model to be set up. This means that minimally three geometrical models are required for a complete solution. The chance of making errors is also multiplied.

In problems where three-dimensional Monte Carlo models are necessary for solving the transport equation, it is practically impossible to obtain the 'average' neutron fluxes in sufficiently fine zones for meaningful coupling to the activation code. ${ }^{10}$ Even if the neutron tallies were made fine enough with an infinite amount of computation time, and the delayed $\gamma$ source distributions calculated correspondingly, efficient sampling from these distributions is still very difficult.

In the following section, we present a new approach which can eliminate these difficulties.

\section{The New Approach: Theory and Algorithm}

In practical calculations of delayed $\gamma$ dose rates due to neutron activation, the solutions are sought only at a few discrete values of $t^{\prime}$. Values at internediate times are obtained by interpolation or extrapolation. This leads to the following interesting consequences.

Eq. (13) may be written in matrix form:

$$
\frac{\partial \mathbf{N}(\vec{r}, t)}{\partial t}=[f(t) \mathbf{A}(\vec{r}, t)+\mathbf{B}] \mathbf{N}(\vec{r}, t) \text {. }
$$

The solution of this equation is, formally,

$$
\mathbf{N}\left(\bar{r}, t^{\prime}\right)=\int_{0}^{t^{\prime}}\left[\int(t) \mathbf{A}(\vec{r}, t)+\mathbf{B}\right] \mathbf{N}(\vec{r}, t) d t
$$

For linear decay chains in which there is no transmutation of nuclides back to their precursors, solution to this equation may be obtained by numerical integration techniques such as the Gear's method ${ }^{20}$ or the matrix exponential method. ${ }^{21}$ To the first order, the solution is given by:

$$
\mathbf{N}(\vec{r}, t+\Delta t) \approx[f(t) \mathbf{A}(\vec{r}, t)+\mathbf{B} ! \mathbf{N}(\vec{r}, t) \Delta t
$$


Thus, given an irradiation history $h\left(t^{\prime}\right)$, which may be defined as the function $f(t)$ for the time interval $0 \leq t \leq t^{\prime}$, the delayed $\gamma$ source is uniquely determined once the neutron flux $\phi_{n}\left(\vec{r}, E_{n}, \bar{\Omega}\right)$ is known. Hence. without loss of generality, the delayed $\gamma$ source corresponding to the history $h\left(t^{\prime}\right)$ may be written as:

$$
S_{r}^{h}\left(\vec{r}, E_{r}, \vec{\Omega}\right) \equiv \iint \phi_{n}\left(\vec{r}, E_{n}, \bar{\Omega}^{\prime}\right) \Sigma^{h}\left(\vec{r}, E_{n}-E_{r}, \bar{\Omega}^{\prime} \rightarrow \vec{\Omega}\right) d E_{n} d \vec{\Omega}^{\prime} .
$$

The notation $S_{\gamma}^{h}\left(\vec{r}, E_{\gamma}, \bar{\Omega}\right)$ is used instead of $Q_{\gamma}\left(\vec{r}, E_{\gamma}, \vec{\Omega}, t^{\prime}\right)$ to emphasize the fact that it is evaluated for the history $h\left(t^{\prime}\right)$ only: The expression $\Sigma^{h}\left(\vec{r}, E_{n} \rightarrow E_{\varphi}, \vec{\Omega}^{\prime} \rightarrow \vec{\Omega}\right)$ may be thought of as the effective double-differential delayed $\gamma$ production cross section at $\vec{r}$. In most practical applications. there is no angular dependence in $\Sigma^{h}$ and, consequently.

$$
S_{r}^{h}\left(\vec{r}, E_{r}, \vec{\Omega}\right)=\frac{1}{4 \pi} \int \rho_{n}\left(\vec{r}, E_{n}\right) \Sigma^{h}\left(\vec{r}, E_{n} \rightarrow E_{r}\right) d E_{n},
$$

where

$\varphi_{n}\left(\vec{r}, E_{n}\right)=\int \phi_{n}\left(\vec{r}, E_{n}, \vec{\Omega}\right) d \vec{\Omega}$ is the scalar neutron fiux, and

$\Sigma^{h}\left(\vec{r}, E_{n} \rightarrow E_{\gamma}\right)=\iint \Sigma^{h}\left(\vec{r}, E_{n} \rightarrow E_{\gamma}, \vec{\Omega}^{\prime} \rightarrow \vec{\Omega}\right) d \vec{\Omega} d \vec{\Omega}^{\prime}$ is the energy-dependent delayed $\gamma$ production cross section due to the irradiation history $h\left(t^{\prime}\right)$.

Another interpretation is that $\Sigma^{h}\left(\vec{r}, E_{n} \rightarrow E_{\gamma}\right) / \Sigma_{T, n}\left(\vec{r}, E_{n}\right)$ is the probability that a neutron collision at the phase point $\left(\vec{r}, E_{n}\right)$ will lead to a delayed $\gamma$ photon of energy $E_{\gamma}$ at $\vec{r}$, given the irradiation history $h\left(t^{\prime}\right)$. This interpretation is useful in Monte Carlo simulations.

The coupled neutron-delayed- $\gamma$ transport equations may, therefore, be written as

$$
\begin{gathered}
\mathcal{L}_{n} \phi_{n}\left(\vec{r}, E_{n}, \vec{\Omega}\right)=S_{n}\left(\vec{r}, E_{n}, \vec{\Omega}\right), \\
\mathcal{L}_{\sim} \phi_{\gamma}^{h}\left(\vec{r}, E_{\gamma}, \vec{\Omega}\right)=S_{\gamma}^{h}\left(\vec{r}, E_{\gamma}, \vec{\Omega}\right)=\frac{1}{4 \pi} \int \phi_{n}\left(\vec{r}, E_{n}\right) \Sigma^{h}\left(\vec{r}, E_{n} \rightarrow E_{\gamma}\right) d E_{n},
\end{gathered}
$$

where we have used $\phi_{\gamma}^{h}\left(\vec{r}, E_{n}, \vec{\Omega}\right)$ in the place of $\Phi_{\gamma}\left(\vec{r}, E_{n}, \vec{\Omega}, t^{\prime}\right)$ to emphasize the dependence on irradiation history.

These equations have exactly the same form as the time-independent, coupled neutronprompt- $\gamma$ transport equations (with isctropic $\gamma$ production cross sections). Consequently, they can be solved in exactly the same way: provided the effective delayed $\gamma$ production cross sections $\Sigma^{h}\left(\vec{r}, E_{n} \rightarrow E_{\gamma}\right)$ are known.

Hence, the post-shutdown dose rate distribution $D^{h}(\vec{r})$ corresponding to the history $h\left(t^{\prime}\right)$ may now be obtained by the following procedure:

(A) Generate the delayed $\gamma$ production cross section $\Sigma^{h}\left(\vec{r}, E_{n} \rightarrow E_{\gamma}\right)$ for all the materials in the system.

(B) Obtain the delayed $\gamma$ flux, $\phi_{\gamma}^{h}\left(\vec{r}, E_{\gamma}, \bar{\Omega}\right)$, by solving the coupled transport Eqs. (19) and $(20)$. 
(C) Fold it with the dose response function $R\left(\vec{r}, E_{\gamma}\right)$ to give $D^{h}(\vec{r})$ :

$$
D^{h}(\vec{r})=\iint \phi_{\gamma}^{h}\left(\vec{r}, E_{\tau}, \vec{\Omega}\right) R\left(\vec{r}, E_{\gamma}\right) d E_{\gamma} d \vec{\Omega}
$$

It is easy to show how the delayed $y$ production cross sections may be calculated. Assuming that the energy variable is treated by the multigroup method, ${ }^{17}$ the coupled multigroup equations may be written as:

$$
\begin{gathered}
\mathcal{L}_{n}^{g} \phi_{n}\left(g_{n}, \vec{\Omega}\right)=S_{n}\left(g_{n}, \vec{\Omega}\right), \\
\mathcal{L}_{\gamma}^{g} \phi_{\gamma}^{h}\left(g_{\gamma}, \vec{\Omega}\right)=S_{\gamma}^{h}\left(g_{r}, \vec{\Omega}\right)=\frac{1}{4 \pi} \sum_{g_{n}^{\prime}} \varphi_{n}\left(g_{n}^{\prime}\right) \Sigma^{h}\left(g_{n}^{\prime} \rightarrow g_{n}\right),
\end{gathered}
$$

where the argument $\vec{r}$ is implied in every function. and $g_{n}, g_{\gamma}$ are, respectively, the neutron and $\gamma$ energr group indjces.

From Eq. (23), if $\varphi_{n}\left(g_{n}^{\prime}\right)$ is zero for all $g_{n}^{\prime} \neq g_{n}$, we have

$$
\Sigma^{h}\left(g_{n} \rightarrow g_{r}\right)=\frac{4 \pi S_{r}^{h}\left(g_{n}-g_{r}, \tilde{\Omega}\right)}{\varphi_{n}\left(g_{n}\right)},
$$

where $S_{\gamma}^{h}\left(g_{n} \rightarrow g_{\gamma}, \vec{\Omega}\right)$ is the delayed $\gamma$ angular source term in group $g_{\gamma}$ due to neutrons in group $g_{n}$. Hence, the multigroup delayed $\gamma$ production cross section $\Sigma^{h}\left(g_{n} \rightarrow g_{\gamma}\right)$ is simply the total delayed $\gamma$ source density in group $g_{\gamma}$ due to unit neutron flux in group $g_{n}$.

Since the materials are assumed to be immobile, there is a unique correspondence between $\vec{r}$ and the material composition at $\vec{r}$. Hence, this matrix depends only on the material and history $h\left(t^{\prime}\right)$, and it may be calculated by a zero-dimensional activation code for all the materials and histories, as part of the cross section generation process. Direct solution for the delayed $\gamma$ dose rate distribution for each irradiation history $h\left(t^{\prime}\right)$ can then be obtained by solving Eqs. (22) and (23) and performing the integration in Eq. (21).

\section{A. Calculations of Delayed Gamma Production Cross Sections}

In general, the calculation of $\Sigma^{h}\left(g_{n} \rightarrow g_{v}\right)$ involves the integration of the matrix Eq. (14) for the irradiation $h\left(t^{\prime}\right)$. Solution algorithms have been implemented in various codes ${ }^{16.22-29}$ for simpie forms of $h\left(t^{\prime}\right)$.

When $h\left(t^{\prime}\right)$ is simple enough, analytic expressions can be obtained for $\Sigma^{h}\left(g_{n} \rightarrow g_{n}\right)$. Some familiar cases are given in the following. 


\section{Periodic Pulsed Operation}

For periodic pulsed operation as depicted in Fig. 1 the activity of the $k^{\text {th }}$ generation nuclide in the linear decay chain $\left\{\eta_{k}\right\}$ due to the neutron flux $\varphi_{n}\left(g_{n}\right)$ is given by':

$$
\begin{aligned}
& A_{k}^{n}=\sum_{i=1}^{k} \sum_{p} V_{p} \sigma_{p}^{i}\left(g_{n}\right) y_{n}\left(g_{n}\right)\left[\prod_{j=i}^{k-1} \beta_{j}\right] \sum_{i=i}^{k}\left(\frac{\prod_{m=i, m \neq l}^{k} \lambda_{m}}{\prod_{m=i, m \neq l}^{k}\left(\lambda_{m}-\lambda_{l}\right)}\right)
\end{aligned}
$$

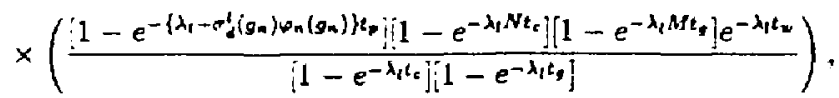

where

$N_{p}=$ number density of nuclide $p$,

$\sigma_{p}^{1}\left(g_{n}\right)=$ group $g_{n}$ average transmutation cross section of $p$ to the $i^{\text {th }}$ generation nuclide in the $\eta$ decay chain,

$\beta_{j}=$ fraction of the $j^{\text {th }}$ generation which decays into the $(j+1)^{\text {th }}$ generation, with the condition

$$
\prod_{j=i}^{k-1} \beta_{j}=1 \text { if } i>k-1,
$$

$\sigma_{d}^{\prime}\left(g_{n}\right)=$ group $g_{n}$ average destruction cross section of nuclide $l$, $\lambda_{l}=$ the decay constant of nuclide $l$, with the condition

$$
\frac{\prod_{m=i, m \neq l}^{k} \lambda_{m}}{\prod_{m=i, m \neq i}^{k}\left(\lambda_{m}-\lambda_{l}\right)}=1 \quad \text { if } i=k,
$$

and we have assumed the initial conditions before irradiation: $A_{k}^{n}=0$, for all $\eta$ and $k$.

The total $\gamma$ source in group $g_{\uparrow}$ will then be given by summing over all the generations in all the independent decay chains, thus,

$$
S_{+}\left(g_{-}\right)=\sum_{n} \sum_{k=1}^{K_{n}} A_{k}^{\eta} Y_{k}^{\eta}\left(g_{r}\right),
$$

where $Y_{k}^{\prime \prime}\left(g_{\gamma}\right)$ is the delayed $\gamma$ yield in group $g_{r}$ for each decay of generation $k$ in ihe chain $\left\{\eta_{k}\right\}, K_{\eta}$ is the maximum number of generations.

By definition, the delayed $\gamma$ production cross section is the delayed $\gamma$ yield for unit neutron flux, thus,

$$
\begin{aligned}
& \Sigma^{h}\left(g_{n} \rightarrow g_{\tau}\right)=\sum_{\eta} \sum_{k=1}^{K_{\eta}} r_{k}^{\eta}\left(g_{r}\right) \sum_{i=1}^{k} \sum_{p} V_{p} \sigma_{p}^{i}\left(g_{n}\right)\left[\prod_{j=i}^{k-1} \beta_{j}\right] \sum_{l=i}^{k}\left(\frac{\prod_{m=i, m \neq l}^{k} \lambda_{m}}{\prod_{m=i, m \neq i l}^{k}\left(\lambda_{m}-\lambda_{l}\right)}\right)
\end{aligned}
$$

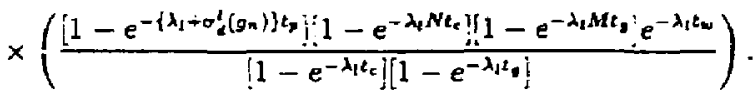

If $V_{p}$ is defined as the isotopic abundance in an element or mixture, then the above gives the microscopic delayed $\gamma$ production cross section. This is useful in studying the effects of individual isotopes or elements. 


\section{Steady-State Operation}

Reduction to steady-state operation may be obtained by setting $M=N=1$, and $t_{p}=t_{c}=t_{g}=t_{o}$, the operation time, in Eq. (13). In this case,

$$
\begin{gathered}
\Sigma^{h}\left(g_{n}-g_{\gamma}\right)=\sum_{\eta} \sum_{k=1}^{K n} Y_{k}^{n}\left(g_{r}\right) \sum_{i=1}^{k} \sum_{p} N_{p} \sigma_{p}^{i}\left(g_{n}\right)\left[\prod_{j=i}^{k-1} \beta_{j}\right] \sum_{l=i}^{k}\left(\frac{\prod_{m=i, m \neq l}^{k} \lambda_{m}}{\prod_{m=i, m \neq l}^{k}\left(\lambda_{m}-\lambda_{l}\right)}\right) \\
\times\left(1-e^{\left.-\left\{\lambda_{l}+\sigma_{d}^{l}\left(g_{n}\right)\right\} t_{o} i e^{-\lambda_{1} l_{v}}\right),}\right.
\end{gathered}
$$

for linear decay chains.

\section{Advantages of the Proposed Method}

The following advantages are rather obvious in this solution scheme:

1) The tedious and error prone process of coupling the neutron flux to an activation code is eliminated. The savings can be very significant for complicated geometries, particularly during the design iterations when they are modified very frequently.

2) The activation and decay processes can be treated on the material by material basis using zero-dimensional (or at most one-dimensional when self-shielding effects are important) codes, which may be made an integral part of the usual cross section mixing operations prior. to the neutron transport calculations. Thus, the number densities of the materials need to be specified only once. The activation calculations required to generate the delayed $\gamma$ production cross sections are much easier and cheaper than the usual spatially-dependent activation calculations, especially for complicated geometry. The coupled neutron-delayed- $\gamma$ cross sections, once generated, may be used repeatedly for analyzing different designs with the same irradiation history.

3) Since the dose calculations can be done with a single self-consistent geometrical model, the errors involved are easier to understand, quantify, and control.

4) By eliminating the need for flux coupling, dose calculations using Monte Carlo methods in three-dimensional geometry become very efficient and desirable, instead of practically impossible. The additional delayed $\gamma$ transport calculations are in most cases only marginally more expensive than the neutron transport ealculations, since the delayed $\gamma$ photons typically suffer very few collisions before their histories are terminated.

\section{An Illustrative Example of Application}

This method of dose rate calculations has been applied to study the shielding design of the vacuum pumping duct in the Compact lgnition Tokamak (ClT). ${ }^{29}$ Figures $2-4$ show 
the geometry of the CIT building structures and the initial design of the pumping duct. Because of the high production level of D-T neutrons in the experimental ignition tokamak, neutron streaming through the big purr.ping duct may lead to high delayed $\gamma$ radiation field in the basement area. The design objective is to make sure shat all equipment in the basement. particularly the vacuum pump. can be maintained 'hands-on' shortly after pulsing the machine. One, therefore. needs to calculate the dose rate in the vicinity of the vacuum pump shortly after machine shutdown. taking into account all the components that are significantly activated.

It is convenient to think of the post-shutdown jose rate at the pump as due to the following components of delaved $\gamma$ fluxes:

(1) Those generated in the pump itself. which give rise to what is usually called the "contact" dose rate.

(2) Those which originate from the tokamak and reach the pump by streaming through the duct.

(3) Those which originate from the duct wall, concrete, and other structures surrounding the duct. and reach the pump by streaming through the duct.

(4) Those which originate from regions other than the pump and reach the pump by penet rating the shielding.

With sufficiently thick shielding around the penetration, the last component may be made arbitrarily small. The first component may be estimated rather easily when the neutron Hux at the pump location is known. The major difficulty is in obtaining reliable estinates of the second and third components for various designs of the duct. Moreover, it is not known which component dominates the dose rate.

The three-dimensional geometry cannot be reduced to an equivalent two-dimensional geometry without significant errors. So, 'all' that is needed is a way to calculate the delayed $\gamma$ distribution and to handle the neutron and $\gamma$ transport in the given three-dimensional geornetry. A deterministic three-dimensional transport code would be ideal for the solution of this problem if it could be made efficient and free of the ray effects. ${ }^{30.31}$ Significant progress has been made in the development of three-dimensional deterministic codes. ${ }^{32-35}$ but no general production codes are readily available.

Hence, one needs to use the Monte Carlo method for rigorous treatment of the threedimensional transport problem. Linfortunately, in Monte Carlo transport calculations, it is practically impossible to obtain sufficiently fine spatial resolution in the neutron flux, which is necessary for coupling to the activation code in the conventional four-step method. The albedo scattering method helps to speed up the calculations but does not eliminate this problem.

The method outlined in previous sections is uniquely suitable for handling this problem. Whether Monte Carlo or deterministic methods are used for solving the three-dimensional 
transport problem, the proposed approach has the distinct advantage of completely eliminating the fiux coupling problems. In principle, once the appropriate delayed $\gamma$ production cross sections are obtained, the dose rate at the locations of interest nay be calculated by a full-blown three-dimensional model containing all the necessary details of the whole facility. Since the state of the art does not permit this. the usual approach in achieving greater efficiency is to break it up into two models which are coupled through the boundary flux.

The steps taken in our solution of the problem were as follows. First, the components (3) and (4) were calculated by the following procedure:

(A) The delayed $\gamma$ production cross sections were calculated with the DKR-ICF code ${ }^{23}$ for relevant materials and irradiation history. This is essentially the evaluation of the expression in Eq. (14). The cross sections were then combined with the neutron transport cross sections, to be used in step (C).

(B) The neutron current at the entrance mouth of the penectration was calculated with a one-dimensional roodel of the tokamak with the ANISN code. ${ }^{30,37}$

(C) A three-dimensional model of the duct and surrounding shield was set up with the MORSE-CG Monte Carlo code, ${ }^{36}$ with the neutron scurce at the entrance given by step (B) above. This step is the solution of the coupled transport Eqs. (11) and (12) by Monte Carlo sampling of the neutron and delayed $y$ histories. A point detector was placed at the approximate pump location to tally the neutron flux and the dose rate.

(D) The design was modified and step (C) was repeated if necessary until the dose rate was sufficiently low.

After that, component (2) was estimated by the following:

(E) The delayed $\gamma$ current at the duct entrance due to the activated tokamal was calculated directly by the ANISN code using the coupled neutron-delayed- $\gamma$ cross sections.

(F) Transport of the delayed $y$ photons through the duct was handled with the MORSE code using the same geometrical model in step (C) and the dose rate was tallied at the same location.

Finally, the 'contact' dose rate was estimated by calculating the delayed $\gamma$ dose rate on the surface of a $4 \mathrm{~cm}$ SS-316 plate using the neutron flux obtained in step (C) as the incident flux. The direct neutron-delayed- $\gamma$ transport calculations were handled by the ANISN code.

The total dose rate would then be a sum of all the components obtained. The following sections give the details in these steps. 


\section{A. Generation of Coupled Neutron-Delayed-Gamma Transport Cross Sections}

The DKR-ICF code was used in the calculation of $\Sigma^{h}\left(g_{n} \rightarrow g_{\gamma}\right)$ for two simple reasons: (1) To avoid the overhead in writing a new program.

(2) Unlike other codes which treat only steady-state operation, such as RACC, ${ }^{26}$ the code contains the algorithms for periodic pulsed operation mode.

A single interval slab geometry was used. The operation history was assumed to be a series of 2016 pulses at one hour apart, each generating 3 GJ of fusion energy. The cooling time was initially set at one hour. Later, some cases were repeated with one-day cooling time to see the effects of longer waiting periods. The activation cross sections were based on the ACTL library ${ }^{39}$ and the decay data were based on the Table of Isotopes ( 7 th ed.). ${ }^{+0}$

The delayed $\gamma$ sources were generated in each material by using unit flux in each of the 46 neutron groups in successive runs. These matrices then replaced the prompt $\gamma$ production matrices in the $46 n-21$ y prompt transport cross sections which were obtained by collapsing the VITAMIN-E data ${ }^{41}$ using the XCNVRT code. ${ }^{42}$ The fine group weighting spectrum was obtained from an ANISN run of a 2-m concrete slab with D-T neutrons incident on one side. $P_{3}$ Legendre expansion was used for all materials. Since the delayed $\gamma$ production was assumed to be isotropic, orders higher than $P_{0}$ are all identically zero.

Figures 5 and 6 show plots of the delayed $\gamma$ production cross sections for ordinary concrete and SS-316, respectively, at one-hour cooling time. In ordinary concrete, the peaks are due primarily to the 2.754 and $1.369 \mathrm{MeV}$ lines in ${ }^{24} \mathrm{Na}$, which is produced largely from the ${ }^{27} \mathrm{Al}(n, \alpha){ }^{24} \mathrm{Na}$ and ${ }^{24} \mathrm{Mg}(n, p){ }^{24} \mathrm{Na}$ reactions at high neutron energies, and from the ${ }^{23} \mathrm{Na}(n, \gamma)^{24} \mathrm{Na}$ reaction at low neutron energies. In SS-316; most of the delayed $\gamma$ photons are from the decay of ${ }^{54} \mathrm{Mn}$ and have an ezergy of $0.8468 \mathrm{MeV}$. At low neutron energies, ${ }^{56} \mathrm{Mn}$ is produced mainly from the ${ }^{55} \mathrm{Mn}(n, \gamma){ }^{56} \mathrm{Mn}$ reaction. At high neutron energies, it results primarily from the ${ }^{\text {B6 }} \mathrm{Fe}(n, p)^{56} \mathrm{Mn}$ reaction.

Since the delayed $\gamma$ production cross sections were several orders of magnitude smaller than the prompt cross sections, they were artificially brought up to the appropriate level which makes the Monte Carlo sampling more efficient. The multiplying factors used in this study were typically on the order of $10^{5}$. The correct normalization was preserved when the tally was divided by the same factor. Alternatively, it would be more desirable to have material-dependent biasing factors and appropriate weight adjustments in the detector tallies, similar to the procedure used in the code MCNP (version $3 B$ ). ${ }^{43,44}$ Generalizations to include energy and spatial dependence would be even more useful.

\section{B. One-Dimensional Model of the Tokamak}

In order to save considerable computational resources, we chose to compromise by using a one-dimensional model of the machine. A realistic three-dimensional NCNP model of 
an older design was already available, ${ }^{45}$ but modifying it to reflect the recent design and implementing the boundary flux coupling to the MORSE penetration model would still be very time consuming. Since the major interest here was to study the effects of various penetration designs on the dose rate, major efforts were spent on the detailed streaming analysis using three-dimensional models of the penetration designs.

A spherical one-dimensional model of the tokamak and the center cell was set up by assuming rotational symmetry for the geometry along the machine midplane about the machine center. The effective density of the TF coils was set at $10 \%$ to account for the considerable neutron leakage through the sections between the discrete coils. $P_{3}-S_{18}$ approximations and the neutron-delayed- $\gamma$ cross sections were used in the same model to give the neutron and delaved- $\gamma$ fluxes for coupling to the penetration model.

\section{Three-Dimensional Penetration Model}

Figures 7 and 8 show the MORSE geometry model of the penetration. The MORSE code was chosen primarily because of the ease in manipulating the cross sections. The multigroup treatment of the energy also makes it fully compatible with all the other codes used.

The SOURCE and SDATA subroutines in MORSE were modified extensively to sample the neutrons from a disk source at the entrance mouth, with the energy and angular distributions as processed by the SOURAN code ${ }^{4 B}$ using the neutron flux from the ANISN model. A next-event estimator was used to tally the neutron and delayed- $\gamma$ fluxes at the detector location. Conversion of the $\gamma$ flux to dose rate was based on the ANS conversion factors. ${ }^{47}$ The importance sampling schemes used were splitting with Russian Roulette and path-lergth stretching.

\section{Results and Discussions}

Table I shows the Hose rates calculated with the above procedure for the initial penetration design (cases No. $1-4$ ).

It is clear that the direct contribution from the tokamak is negligible compared to the other components. The major contribution comes from the activated materials around the penetration. The 'contact' dose rate is usually somewhat less, but may be more inportant under certain circumstances, e.g., case No. 1.

Boron added to the concrete is very effective in suppressing the delayed $\gamma$ generation, primarily because ${ }^{10} \mathrm{~B}$ is very effective in capturing low energy neutrons which might otherwise be absorbed in ${ }^{23} \mathrm{Na}$ to form ${ }^{24} \mathrm{Na}$, the dominant $\gamma$ emitter in ordinary concrete a few hours after shutdown. The SS-316 pipe wall leads to a much higher dose rate when the concrete is borated because of additional radionuclides generated, primarily ${ }^{56} \mathrm{Mn}$. However, 
without the presence of boron in concrete, the steel pipe actually results in a lower dose rate because of its combined neutron absorption and shielding effects.

Because of the difficulties in establishing the probable maintenance schedules and procedures, the acceptable dose level for "hands-on' maintenance cannot be rigidly defined. The guideline that has been adopted here is that the design should achieve a dose rate of $<0.10$ $\mathrm{mSv} / \mathrm{h}$ after one hour of cooling.

The total dose rates in Table I all exceed this design level. Hence, a modified penetration design shown in Figures 9 and 10 was examined. This design consists of two more bends in the penetration, which should lead to significant attenuation in the neutron flux. Since all the bends are in the enclosed space between the inner and outer basement areas, the design does not lead to any loss of useful diagnostic floor space.

The results for this modifed design are given in the last row (case No. 5) of Table I. The total dose rate is $<0.10 \mathrm{mSv} / \mathrm{h}$ after one hour of cooling.

The $0.10 \mathrm{mSv} / \mathrm{h}$ design guideline is rather conservative. Since the major isotopes have half-lives of a few hours (14.97 $\mathrm{h}$ for ${ }^{24} \mathrm{Na}$ and $2.579 \mathrm{~h}$ for ${ }^{58} \mathrm{Mn}$ ), the dose rate could be reduced by more than a factor of 10 after one day of cooling. To assess this effect, the penetration contribution in case No. 3 was calculated for a one-day cooling time. The result was $0.043 \pm 16 \%$ and $0.024 \pm 24 \% \mathrm{mSv} / \mathrm{h}$ for the penetration and contact components, respectively, giving an 'effective half-life' of about 5.9 hours. A similar reduction factor should be applicable to the modified design. Thus, the dose rate in this case after one day of cooling should be $<10 \mu \mathrm{Sv} / \mathrm{h}$. Also, during the period between one hour and one day after shutdown, the integrated dose that an individual mav receive is about $0.57 \mathrm{mSv}$, which gives an hourly averaged dose rate of about $25 \mu \mathrm{Sv} / \mathrm{h}$. Thus, hands-on maintenance of the vacuum pump should be feasible as early as a day after shutdown.

It is obvious that further iterations may be carried out with the present method to optimize the design with respect to other factors such as cost and space. They will be necessary when the project enters the detailed engineering design phase.

\section{Conclusions}

We have shown in this paper that in cases where the quasi-static approximation is applicable, the tedious and error prone flux coupling procedure in the conventional delayed $\gamma$ dose rate calculations can be eliminated by using the delayed $\gamma$ production cross section formulation. This new approach is especially useful for dealing with complex geometries which require three-dimensional Monte Carlo models for rigorous transport calculations. The elimination of flux coupling makes the transport calculations self-consistent in all aspects. 


\section{Possible Improvements and Generalizations}

To realize the full benefits of the proposed method, the generation of the delayed $\gamma$ production cross sections should be made an integral part of the transport cross section generation and mixing operation. In addition, equivalent 'reaction cross sections' may be defined for other responses of interest, such as the delayed $B$ and $\gamma$ heat deposition, and inserted in the approriate positions in the cross section matrix, so that they may be obtained at the same time in the transport calculations.

By making the actiration calculations the equivalent of cross section processing, the uncertainties in these calculations can be characterized with the standard techniques of cross section sensitivity analysis. ${ }^{4}$ Perturbation techniques used in shield optimization for prompt responses ${ }^{9-51}$ may also be applied to find the configuration for optimal delayed responses such as artivity, dose rate. and decay heat generation.

To avoid the need for repeated neutron transport calculations in a Monte Carlo model for different irradiation histories, a generalized group structure may be defined, which would include, in one matrix, all the delayed $\gamma$ production cross sections for different histories. Communications between the different histories can be prohibited by setting the cortesponding $\gamma$ transfer cross sections to zero. This technique can also be applied to a deterministic transport model to obtain all the distributions of all responses of interest in a single calculation. In principle, the generalized group structure can be made to include other processes such as charge particle transport, ${ }^{52}$ and activation due to charge particles or photons, with appropriate modifications in the transport codes.

Although the calculations have been illustrated with the multigroup treatment of the energy variable and $P_{3}$ Legendre expansion of the angular variable in the cross sections, the method is not restricted as such. The neutron energy (and photon energy, although its usefulness in this case is doubtful) variable may be treated by the discrete energy ${ }^{\mathbf{5 3}}$ or hybrid ${ }^{54,55}$ method for the deterministic transport solution. In this case, $g_{n}$ in Eq. (22) simply becomes the neutron energy grid-point/group index, with the appropriate quadrature weights attached to $\Sigma^{h}$ for evaluating the delayed $\gamma$ source in Eq. (23). The same energy treatment should, of course, be preserved in the generation of cross sections. The 'continuous' energy treatment in Monte Carlo codes such as MCNP44 is also applicable, when the probabilistic interpretation of $\Sigma^{h}$ is used. These schemes are capable of more faithful representations of the rapid variations in the cross sections, which are very common near the thresholds of many activation processes. We note that a patch already exists in MCNP that can sample photons from a distribution of radioactive nuclides. ${ }^{\text {se }}$ Generalization of this patch to include the history function of the radionuclide distribution should be straightforward.

For the angular variable, all other techniques can be used. For example, the doubledifferential treatment ${ }^{58,57}$ in the MORSE-DD ${ }^{59}$ or DOT-DD code, ${ }^{60}$ and the equi-probable bin treatment in MCNP ${ }^{44,61}$ are much more useful in modelling delayed $\gamma$ streaming through small penetrations. Finally, if repeated calculations need to be made with the same data set, but for different penetration geometries, a coupled neutron-delayed- $\gamma$ albedo data set may 
be generated to speed up the subsequent transport calculations.

Most of these generalizations require the implementation of specific codes for the calculations of delayed $\gamma$ production cross sections in the specific formats required. We believe that efforts should be made to make them available as soon as possible.

\section{Acknowledgement}

This work was supported by the U.S. Department of Energy Contract No. DE-ACO276-CHO-3073. 


\section{Appendix: Definitions of Symbols}

- $\vec{r}$ : position vector.

$E_{n}, E_{n}^{\prime}:$ neutron energy.

$E_{\sim}, E_{\gamma}^{\prime \prime} \gamma$ energy.

$\vec{\Omega}, \vec{\Omega}^{\prime}$ : direction or angular vector.

$t, t^{\prime}:$ time variables.

$v$ : speed of neutrons.

$c$ : speed of photons.

$\Phi_{n}\left(\vec{r}, E_{n}, \vec{\Omega}, t\right)$ : time-dependent neutron flux distribution.

$\Phi_{\gamma}\left(\vec{r}, E_{\gamma}, \vec{\Omega}, t^{\prime}\right)$ : time-dependent delayed $\gamma$ flux distribution.

$Q_{n}\left(\vec{r}, E_{n}, \vec{\Omega}, t\right)$ : time-dependent neutron source distribution.

$Q_{\gamma}\left(\vec{r}, E_{\sim}, \vec{\Omega}, t^{\prime}\right)$ : time-dependent delayed $\gamma$ source distribution.

$R\left(\vec{r}, E_{\varphi}\right)$ : dose response function.

$D\left(\vec{r}, t^{\prime}\right):$ dose rate distribution.

$\mathcal{L}_{n}$ : linear Boltzmann neutron transport operator.

$\mathcal{L}_{\text {: }}$ linear Boltzmann $\boldsymbol{\gamma}$ transport operator.

$\Sigma_{T, n}\left(\vec{r}, E_{n}\right):$ macroscopic total neutron interaction cross section.

$\Sigma_{T_{i},}\left(\vec{r}, E_{\gamma}\right)$ : macroscopic total $\gamma$ interaction cross section. section.

$\Sigma_{,, n}\left(\vec{r}, E_{n}^{\prime} \rightarrow E_{n}, \vec{\Omega}^{\prime} \rightarrow \vec{\Omega}\right):$ double-differential macroscopic neutron scattering cross $\Sigma_{s, \gamma}\left(\vec{r}, E_{\gamma}^{\prime} \rightarrow E_{\gamma}, \vec{\Omega}^{\prime} \rightarrow \vec{\Omega}\right):$ double-differential macroscopic $\gamma$ scattering cross section. tively.

$\lambda_{i}, \lambda_{m}, \lambda_{l}:$ radioactive disintegration constants of nuclides identified by $i, m, l$, respec-

$\lambda_{j \rightarrow i}$ : radioactive disintegration constant of nuclide $j$ into nuclide $i$.

$N_{i}, N_{j}, N_{k}, N_{p}$ : number densities of nuclides identified by $i, j, k, p$, respectively.

$Y_{i}\left(E_{\gamma}, \vec{\Omega}\right)$ : energy and angular distribution of the decay $\gamma$ photons emitted by nuclide $i$ 
$\sigma_{k \rightarrow i}\left(\vec{r}, E_{n}\right):$ microscopic transmutation cross section from nuclide $k$ into nuclide $i$.

$\sigma_{i}^{d}\left(\vec{r}, E_{n}\right)$ : microscopic destruction cross section of nuclide $i$.

$S_{n}\left(\vec{r}, E_{n}, \vec{\Omega}\right)$ : time-independent neutron source distribution.

$f(t)$ : time-varying part of the neutron source distribution.

$h\left(t^{\prime}\right)$ : the neutron irradiation history function. function.

$\dot{\phi}_{n}\left(\vec{r}, E_{n}, \vec{\Omega}\right)$ : time-independent neutron flux distribution, or the neutron flux shape $\hat{r}_{n}\left(\vec{r}, E_{n}\right):$ time-independent scalar (or total) neutron flux distribution.

$\Sigma^{h}\left(\vec{r} . E_{n} \rightarrow E_{r}, \vec{\Omega}^{\prime} \rightarrow \vec{\Omega}\right):$ effective double-differential delayed $\gamma$ production cross section at $\vec{r}$, resulting from the irradiation history $h\left(t^{\prime}\right)$.

$\Sigma^{h}\left(\vec{r}, E_{n} \rightarrow E_{\gamma}\right):$ energy dependent delayed $\gamma$ production cross section at $\vec{r}$ due to the irradiation history $h\left(t^{\prime}\right)$.

$\phi_{\gamma}^{h}\left(\vec{r}, E_{\gamma}, \vec{\Omega}, t^{\prime}\right)$ : delayed $\gamma$ flux distribution due to the neutron source $S_{n}\left(\vec{r}, E_{n}, \vec{\Omega}\right)$ and the irradiation history $h\left(t^{\prime}\right)$.

$S_{\gamma}^{h}\left(\vec{r}, E_{\gamma}, \vec{\Omega}\right)$ : delayed $\gamma$ source distribution due to the neutron source $S_{n}\left(\vec{r}, E_{n}, \vec{\Omega}\right)$ and the irradiation history $h\left(t^{\prime}\right)$.

$D^{h}(\vec{r})$ : delayed $\gamma$ dose rate distribution due to the neutron source $S_{n}\left(\vec{r}, E_{n}, \vec{\Omega}\right)$ and the irradiation history $h\left(t^{\prime}\right)$.

$g_{n}, g_{\gamma}:$ neutron and $\gamma$ energy group indices.

$\mathcal{C}_{n}^{g}, \mathcal{L}_{\mathrm{n}}^{s}$ : multigroup forms of $\boldsymbol{C}_{\mathrm{n}}$ and $\boldsymbol{C}_{\mathrm{r}}$.

$\phi_{n}\left(g_{n}, \vec{\Omega}\right)$ : multigroup form of $\phi_{n}\left(\vec{r}, E_{n}, \vec{\Omega}\right)$.

$S_{n}\left(g_{n}, \vec{\Omega}\right):$ multigroup form of $S_{n}\left(\vec{r}, E_{n}, \vec{\Omega}\right)$.

$\phi_{\gamma}^{h}(g, \vec{\Omega})$ : multigroup form of $\phi_{\gamma}^{h}\left(\vec{r}, E_{r}, \vec{\Omega}, t^{\prime}\right)$.

$S_{\gamma}^{h}\left(g_{\gamma}, \vec{\Omega}\right)$ : multigroup form of $S_{\uparrow}^{h}\left(\vec{r}, E_{\gamma}, \vec{\Omega}\right)$.

$\Sigma^{h}\left(g_{n}^{\prime} \rightarrow g_{r}\right):$ multigroup form of $\Sigma^{h}\left(\vec{r}, E_{n} \rightarrow E_{r}\right)$. 


\section{References}

${ }^{1}$ L. P. KU and J. G. KOLIBAL, "Radicactivation Characteristics for the Tokamak Fusion Test Reactor." Nucl. Technol.jFusion, 4, 586, (1983).

${ }^{2}$ L. P. KU and J. G. KOLIBAL, "Estimated Neutron Activation DATA for TFTR, Part II: Biological Dose Rate from Sample Material Activation," PPPL-1898, Princeton Plasma Physics Laboratory (1982).

${ }^{3}$ H. J BROCKMANN and U. OHLIG, "Activation from D-T Fusion Neutrons and Resulting Dose Rates in JET," Proc. 9th Symp. on Fusion Technol., Pergamon Press, New York. $(1976)$.

${ }^{`}$ D. L. HENDERSON, M. E. SAWAN, and G. A. MOSES, "Radiological Dose Calculations for the Diode Region of the Light lon Fusion Target Development Facility," Fusion Technoi., 13, 594, (1988).

${ }^{5} \mathrm{H}$. IIDA, Y. SEKI, and T. IDE, "Induced Activity and Dose Rates in the JAERI Experimental Fusion Reactor (JEFR)," JAERI-M-6639, Japan Atomic Energy Research Institute, (1977).

${ }^{6} Y$. SEKI, H. KAWASAKI, and S. MORI, "Radiation Shielding Considerations for the Repair and Maintenance of A Swimming Pool Type Tokamak Reactor," Nucl. Eng. and Design/Fusion, 1, 243, (1984).

${ }^{7}$ G. PRILLINGER, A. FISCHER, E. FISCHER, and K. KRACSE, "Prompt and Delayed Radiation Shielding Calculations for the Zephyr Deuterium-Tritium Ignition Experiment," Nucl. Technol./Fusion, 2, 301, (1982).

${ }^{8}$ R. G. ALSMILLER, Jr., T. A. GABRIEL, and J. BARISH, "Photon Dose from Induced Activity in the BEAM Stop of a $400 \mathrm{GeV}$ Proton Accelerator," Nucl. Instrum. Methods, 155, 399, (1978).

${ }^{9}$ R. G. ALSMILLER, Jr. et al., "Dose Rates from Induced Activity in the Tokamak Fusion Test Reactor Test Cell," Nucl. Technol., 48, 187, (1980).

${ }^{10}$ T. R. HILL and W. H. REED, "TIMEX: A Time-Dependent Explicit Discrete Ordinates Program for the Solution of Multigroup Transport Equations with Delayed Neutrons," LA-6201-MS, Los Alamos National Laboratory, (1976).

${ }^{11}$ K. D. LATHROP, R. E. ANDERSON, and F. W. BRINKLEY, "TRANZIT: A Program for Multigroup Time-Dependent Transport in $(\rho, z)$ Cylindrical Geometry," LA-4575, Los Alamos National Laboratory, (1971).

${ }^{12}$ T. B. FOWLER and D. R. VONDY, "Nuclear Reactor Core Analysis Code: CITATION," ORNL-TM-2496, Rev. 2, Oak Ridge National Laboratory, (1971). 
${ }^{13}$ R. J. BREEY. O. J. MARLOWE, and C. J. PFEIFER, "HARMONY: System for Yuclear Reactor Depletion Computation," WAPD-TM-478, Bettis Atomic Power Laboratory, (1965).

"R. F. BARRY, "LEOPARD, A Spectrum Dependent Nion-Spatial Depletion Code for the IBMI-7094," WCAP-3741, Westinghouse Electric Corporation, (1963).

${ }^{15}$ T. R. ENGLAND, "CINDER, A One-Point Depletion and Fission Product Program," WAPD-TM-334, Bettis Atomic Power Laboratory, (1962).

${ }^{16}$.I. J. BELL, "ORIGIN - The ORNL Isotope Generation and Depletion Code," ORNL4628, Oak Ridge National Laboratory, (1973).

${ }^{17}$ G. I. BELL and S. GLASSTONE, "Nuclear Reactor Theory" Van Nostrand Rienhold, New York, (1970).

${ }^{16}$ W. M. STACEY, Jr., "Space-Time Nuclear Reactor Kinetics," Academic Press, New York, (1969).

${ }^{29} \mathrm{~J}$. BERISH, T. A. GABRIEL, and R. G. ALSMILLER, Jr., "MAGIK: A Monte Carlo System for Computing Induced Residual Activation Dose Rates," ORNL-5561, Oak Ridge National Laboratory, (1979).

${ }^{20} \mathrm{C}$. W. GEAR, "Numerical Initial Value Problems in Ordinary Differential Equations," Prentice-Hall, Englewood Cliffs, (1971).

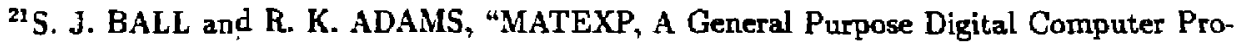
gram for Solving Ordinary Differential Equations by the Matrix Exponential Method," ORNL-TM-1933, Oak Ridge National Laboratory, (1967)

${ }^{22} \mathrm{~L}$. P. KU and J. KOLIBAL, "REBATE/PP_C: One and Two Dimensional Activation Analysis Code, A User's Guide," EAD-R-4, Princeton Plasma Physics Laboratory Engineering Analysis Division, (1982).

${ }^{23}$ D. L. HENDERSON and O. YASAR, "DKR-ICF: A Radioactivity and Dose Rate Calculation Code Package," UWFDM-714, Vol. 1 \& 2, University of Wisconsin-Madison, (1987).

${ }^{24}$ T. Y. SUNG and W. F. VOGELSANG, "DKR: A Radioactivity Calculation Code for Fusion Reactors," UWFDM-170, University of Wisconsin-Madison, (1976).

${ }^{25}$ Y. SEKI, H. IIDA, H. KAWASAKI, and K. YAMADA, "THIDA-2: An Advanced Code System for Calculation of Transmutation, Activation, Decay Heat and Dose Rate," JAERI-1301, Japan Atomic Energy Research Institute, (1986).

${ }^{20} \mathrm{~J}$. JUNG, "Theory and Use of the Radioactivity Code RACC," ANL/FPP/TM-122, Argonne National Laboratory, (1979). 
${ }^{27}$ R. M. LESSLER, W. E. ALLEY, and J. B. GREEN, "ACT and ACTIVE Codes for Calculating Neutron-Induced Activation," UCRL-51292, Lawrence Livermore National Laboratory, (1978).

${ }^{28}$ F. M. MANN, "Transmutation of Allovs in MFE Facilities as Calculated by REAC (A Computer Code System for Activation and Transmutation)," HEDL-TME 81-37, Hanford Engineering Development Laboratory, (1982).

${ }^{29}$ J. A. SCHMIDT and H. P. FURTH, "Compact Ignition Tokamak Conceptual Design Report," A-860606-P-01, Princeton Plasma Physics Laboratory, (1986).

${ }^{30}$ K. D. LATHROP. "Ray Effects in Discrete Ordinaies Equations," Nucl. Sci. Eng., 32, $357,(1968)$.

${ }^{31}$ K. D. LATHROP, "Remedies for Ray Effects," Nucl. Sci. Eng. , 45, 255, (1971).

${ }^{32}$ W. A. RHOADES and R. L. CHILDS, "The TORT Three-Dimensional Discrete Ordinates Neutron/Photon Transport Code," ORNL-6268, Oak Ridge National Laboratory, (1987).

${ }^{33}$ Z. SUZLOKI, K. IKEDA, T. NISHIMURA, K. TADA, H. YOKOBORI, and Y. KAISE, "Recent Development and Current Application of Three-Dimensional Discrete Ordinates Transport Codes," Prac. ANS Top. Mtg. on Reactor Phys. and Shielding, 1, 208, (1984).

${ }^{34}$ T. IDA, S. KONDO, Y. TOGO, and Y. OKA, "Development of Radiation Transport Code in Three-Dimensional (X, Y, Z) Geometry for Shielding Analyses by Direct Integration Method," J. Nucl. Sci. Technol. 24(3), 181, (1987).

${ }^{35}$ T. FUJIMA, Y. NAKAHARA, and M. MATSUMURA, "Solution of Three-Dimensional Neutron Transport Equation by Double Finite Element Method," J. Nucl. Sci. Technol., 20(7), 620, (1983).

${ }^{36}$ W. W. ENGLE, Jr., "The Users Manual for ANISN: A One-Dimensional Discrete Ordinates Transport Code with Anisotropic Scattering," K-1694, Oak Ridge Gaseous Diffusion Plant, (1967).

${ }^{37} \mathrm{~L}$. P. KL' and J. KOLIBAL, "ANISN/PPL-C, A One-Dimensional Multigroup Discrete Ordinates Code, A User's Guide," EAD-R-11, Princeton Plasma Physics Laboratory Engineering Analysis Division, (1982).

38 "MORSE-CG: A General Purpose Monte Carlo Multigroup Neutron and Garnma-Ray Transport Code with Combinatorial Geometry," RSIC Computer Code Collection, CCC-203.

${ }^{30}$ M. A. GARDNER and R. O. HOWERTON, -ACTL: Evaluated Neutron Activation Cross Section Library - Evaluation Techniques and Reaction Index," UCRL-50400, 18, Lawrence Livermore National Laboratory, (1978).

${ }^{{ }^{\circ} \mathrm{C} .}$ M. LEDERER, et al, "Table of Isotopes (7th Edition)," John Wiley \& Sons, (1978). 
41 "VITAMIN-E: A Coupled 174 Neutron, 38 Gamma-Ray Multigroup Cross-Section Library for Deriving Application Dependent Working Libraries for Radiation Transport Calculations," DLC-113, RSIC Data Library Cclection, Oak Ridge National Laboratory, $(1987)$.

${ }^{42}$ L. P. KU and J. KOLIBAL, "XCNVRT: A Multigroup Cross Section Collapsing Code, A L'ser's Guide," EAD-R-7. Princeton Plasma Physics Laboratory Engineering Analysis Division, (1982).

${ }^{43}$ J. BRIESMEISTER, MCNP3B Newsletter. Los Alamos National Laboratory (July 18. 1988).

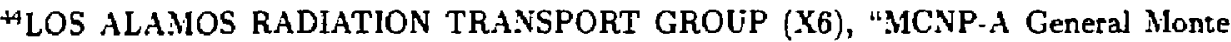
Carlo Code for Neutron and Photon Transport, Version 3A," LA-7396-M, Rev. 2, Los Alamos National Laboratory, (1986).

${ }^{45}$ S. L. LIEW and L. P. KL, "An Assessment of the CIT Radiation Environment Using Coupled Three-Dimensional and Reduced Transport Models," Proc. 12th Symp. on Fusion Engineering, Monterey, CA, Oct. 12-16, (1987).

${ }^{46}$ L. P. KU, J. KOLIBAL, and S. L. LIEW, "SOURAN, A Source Processor for ANISN," Princeton Plasma Physics Laboratory Engineering Analysis Division, (unpublished).

${ }^{47}$ “American Standard Neutron and Gamma-Ray Flux-to-Dose-suate Factors, ${ }^{\prime}$ ANS1/ANS$6.11,(1977)$.

${ }^{40}$ D. E. BARTINE, E. M. OBLOW, and F. R. MYNATT, "Radiation Transport Cross Section Sensitivity Analysis - A General Approach Illustrated for a Thermonuclear Source in Air," Nucl. Sci. Eng., 55, 147, (1974).

${ }^{49}$ E. GREENSPAN, W. G. PRICE, Jr., and H. FISHMAN, "SWAN: A Code for the Analysis and Optimization of Fusion Reactor Nucleonic Characteristics," MATT-1008, Princeton Plasma Physics Laboratory, (1973).

${ }^{50}$ E. GREENSPAN, "A Method for the Optimization of Fusion Reactor Neutronic Characteristics," Proc. Conf. Math. Models and Comp. Techniques for Analysis of Nuclear Systems, Ann Arbor, MI, p. 162, (1973).

${ }^{51}$ E. GREENSPAN, D. GILAI, and E. M. OBLOW, "Second-Order Generalized Perturbation Theory for Source-Driven System," Nucl. Sci. Eng., 68, 1, (1978).

${ }^{52}$ L. J. LORENCE, W. E. NELSON, and J. E. MOREL, “Coupled Electron-Photon Transport Calcuiations Using the Method of Discrete Ordinates," LA-UR-85-962, Los Alamos National Laboratory, (1986).

${ }^{53}$ J. CHING. H. GOLDSTEIN, and E. OBLOW, "Application of a Discrete Energy, Discrete Ordinates Technique to the Study of Neutron Transport in Iron," ORNL-TM-4235, Oak Ridge National Laboratory, (1974). 
${ }^{54}$ Y.-W. H. LIU and H. GOLDSTEIN, "Neutron Transport Calculations Involving a Mixture of Group and Discrete Energy Fluxes," Proc. Am. Nucl. Soc. Top. Conf. on 1980 Advances in Reactor Physics and Shielding, (1980).

${ }_{55}^{5}$ Y.-W. H. LIU, "Calculational Benchmark for Neutron Penetration in Iron," Proc. ANS Top. Mtg. on Reactor Phys. and Shielding, 2, 555, (1984).

${ }^{56}$ G. P. ESTES, R. G. SCHRANDT, and J. T. KRIESE, "Automated MCNP Photon Source Generation for Arbitrary Configurations of Radioactive Materials and First-Principles Calculations of Photon Detector Responses," LA-11153-MS, Los Alamos National Laboratory, (1988).

${ }^{57}$ T. MORI, M. NAKAGAWA, and Y. ISHIGLRO, "PROF-DD, A Code System for Generation of Multigroup Double Differential Form Cross Section Library," JAERI-M 86-124. Japan Atomic Energy Research Institute, (1986).

50 T. MORI, M. NAKAGAWA and M. SASAKI, "One-, Two- and Three-Dimensional Transport Codes Lising Multi-Group Double-Differential Form Cross Sections," JAERI-1314, Japan Atomic Energy Research Institute, (1986).

${ }^{50}$ M. NAKAGAWA and T. MORI, "MORSE-DD, A Monte Carlo Code Using Multi-Group Double Differential Form Cross Section," JAERI-M 84-126, Japan Atomic Energy Research Institute, (1984).

${ }^{80}$ T. MORI and M. SASAKI, "Development of a 2-D $S_{n}$ Transport Code Using Double Differential Form Cross Section Library," JAERI-M 86-125, Japan Atomic Energy Research Institute, (1986).

${ }^{61}$ L. L. CARTER and C. A. FOREST, "Transfer Matrix Treatments for Multigroup Monte Carlo Calculations - The Elimination of Ray Effects," Nucl. Sci. Eng., 59, 27, (1976).

62 "Guidelines on the Nuclear Analysis and Design of Concrete Radiation Shielding for Nuclear Power Plants," ANSI Standards No. ANSI/ANS-6.4-1977 (N403). 


\begin{tabular}{|l|l|l|l|l|l|}
\hline Case & Concrete & SS-316 Pipe & \multicolumn{3}{|c|}{ Dose Rate (mSv/h) due to } \\
No. & Borated? \pm & Present? & Penetration & Contact & Tolamak \\
\hline 1 & Yes & No & $0.09 \pm 16 \%$ & $0.27 \pm 12 \%$ & $0.018 \pm 9 \%$ \\
2 & No & No & $6.39 \pm 12 \%$ & $2.15 \pm 12 \%$ & $0.018 \pm 9 \%$ \\
3 & Yes & Yes & $0.63 \pm 15 \%$ & $0.48 \pm 14 \%$ & $0.016 \pm 16 \%$ \\
4 & No & Yes & $4.38 \pm 28 \%$ & $1.21 \pm 15 \%$ & $0.016 \pm 16 \%$ \\
\hline 5 & Yes & Yes & $0.046 \pm 33 \%$ & $0.033 \pm 26 \%$ & $\sim 0.002 \dagger$ \\
\hline
\end{tabular}

† Scaled from the previous cases.

\$ The concrete composition was assumed to be that of ANSI Type $4,{ }^{02}$ and the boron content was assumed to be $0.8 \%$ by weight boron for borated concrete.

Table l: Dose rate at one hour after shutdown due to various components of the delayed $\gamma$ flux for various penet ration configurations. The uncertainties are $1 \sigma$ deviations due only to the statistics in the Monte Carlo simulations. 


\section{List of Figures}

Figure 1: Schematic representation of a periodic pulsed operation mode.

Figure 2: A vertical cross section of the CIT building showing the tokamak in the center cell and the initial routing of the vacuum pumping duct.

Figure 3: A horizontal cross section (view A-A of Fig. 2) of the CIT center cell showing the location of the vacuum pumping duct penetration through the floor.

Figure 4: A horizontal cross section (view B-B of Fig. 2) of the CIT basement area showing the vacuum pumping system.

Figure 5: The delayed $\gamma$ production cross section matrix of ordinary concrete at one hour cooling time. time.

Figure 6: The delayed $\gamma$ production cross section matrix of SS-316 at one hour cooling

Figure 7: A vertical cross section of the three-dimensional MORSE geometry model of the initial penetration design.

Figure 8: A horizontal cross section of the three-dimensional MORSE geometry model of the initial penetration design.

Figure 9: A vertica! cross section of the three-dimensional MORSE geometry model of the modified penetration design.

Figure 10: A horizontal cross section of the three-dimensional MORSE geometry model of the modified penetration design. 
Number of Groups in a Run, M

Number of Pulses in a Group, N
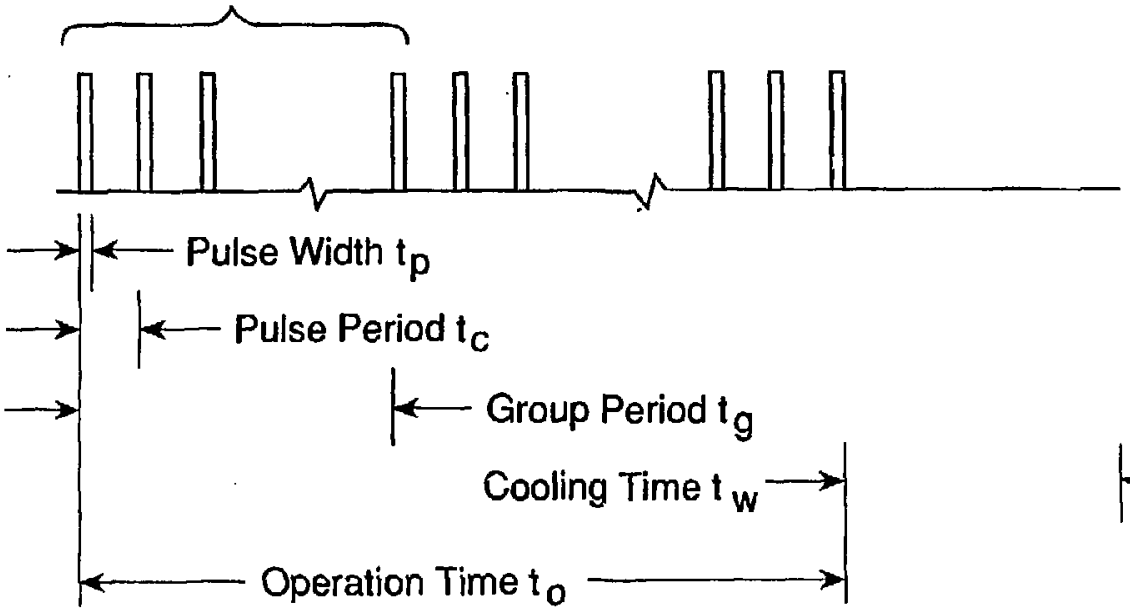


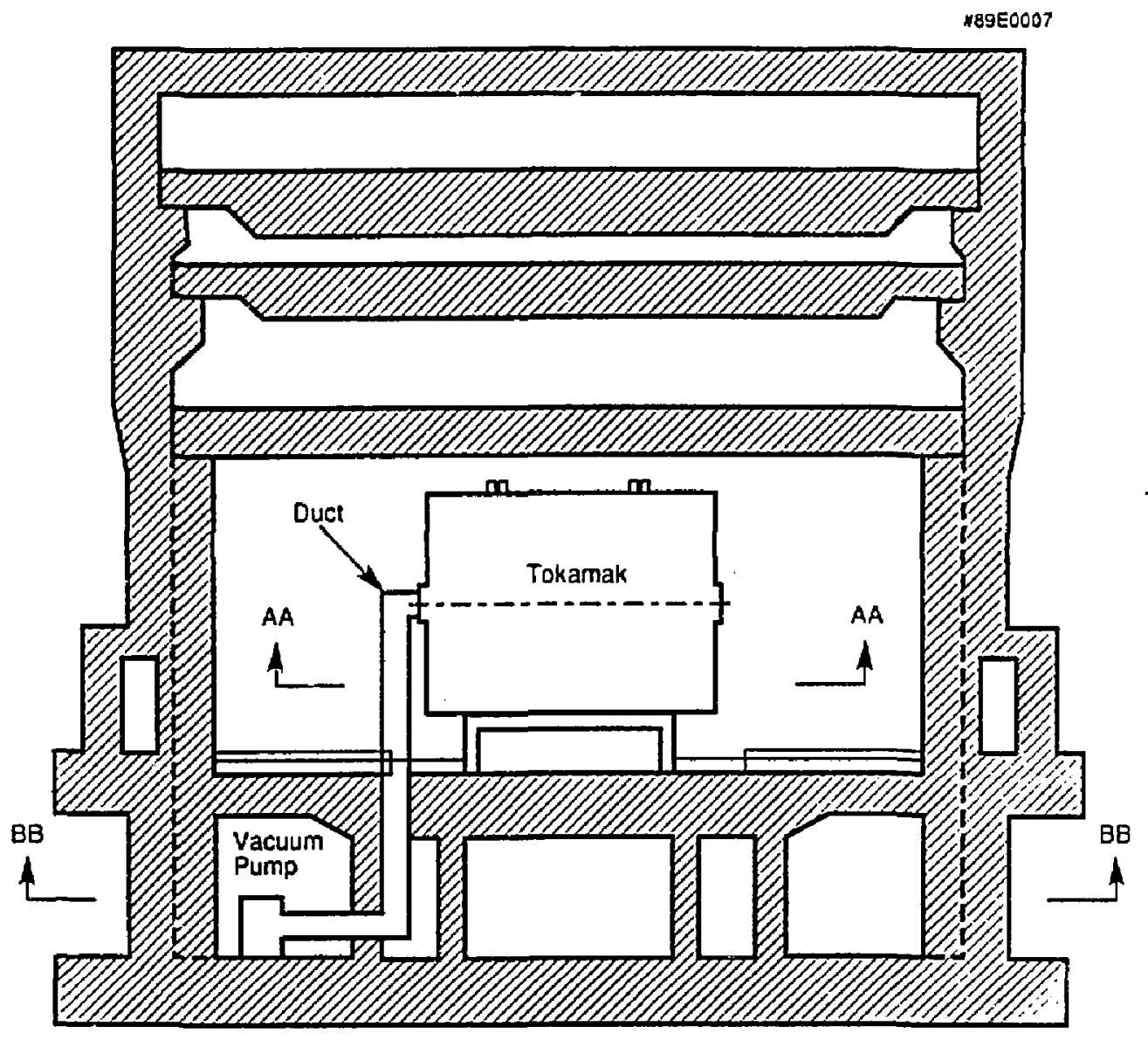

Fig. 2 
\#89E0012

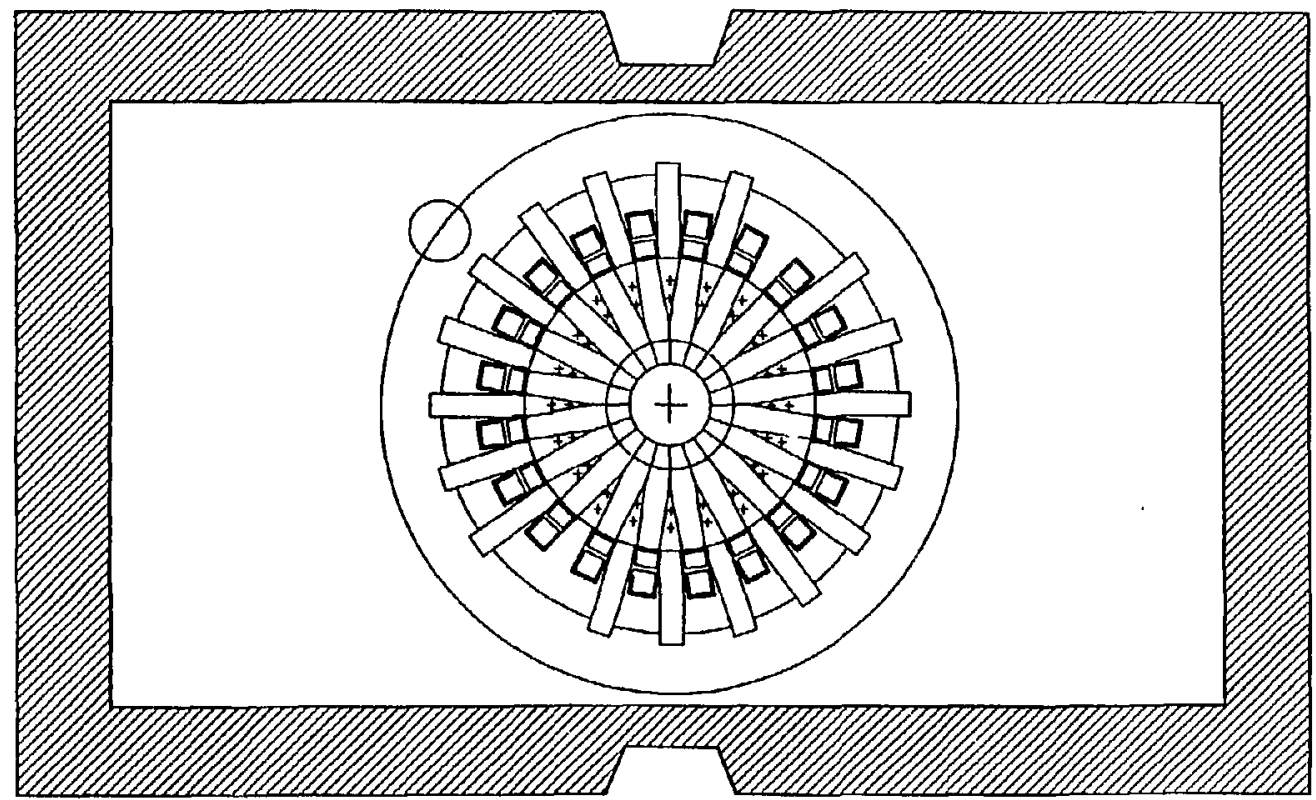

VIEW A-A

Fig. 3 


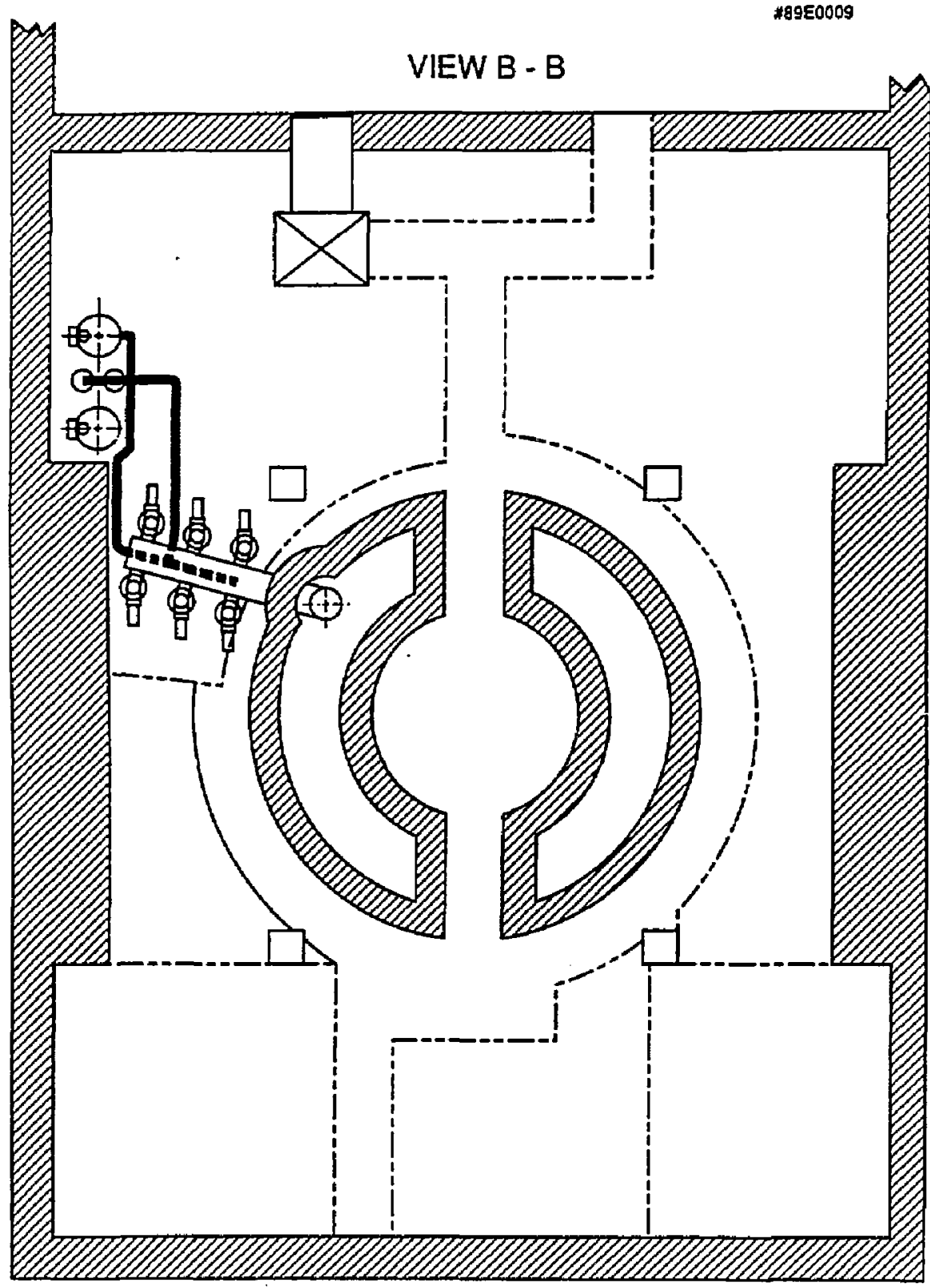

Fig. 4 


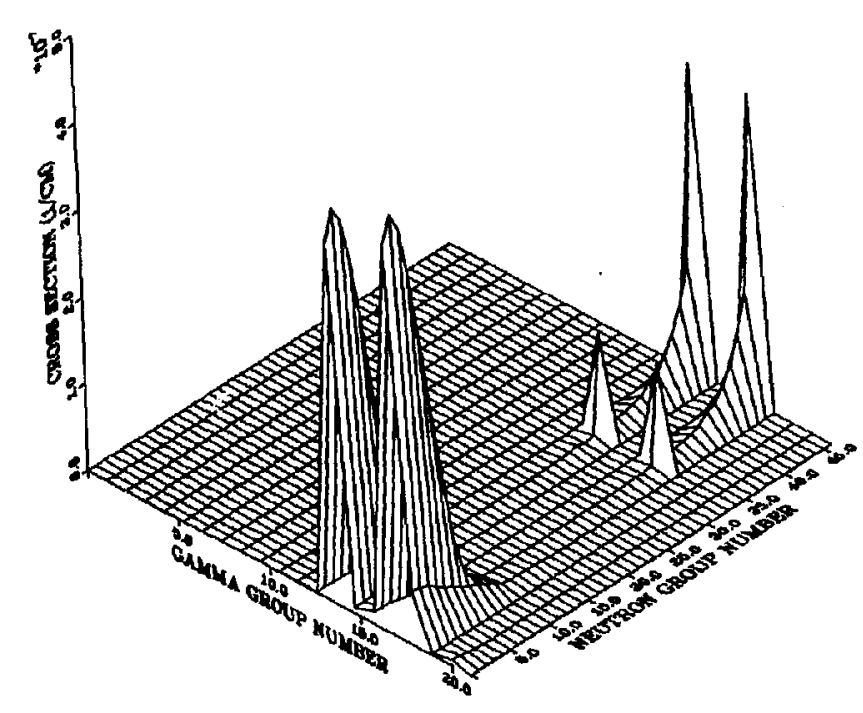




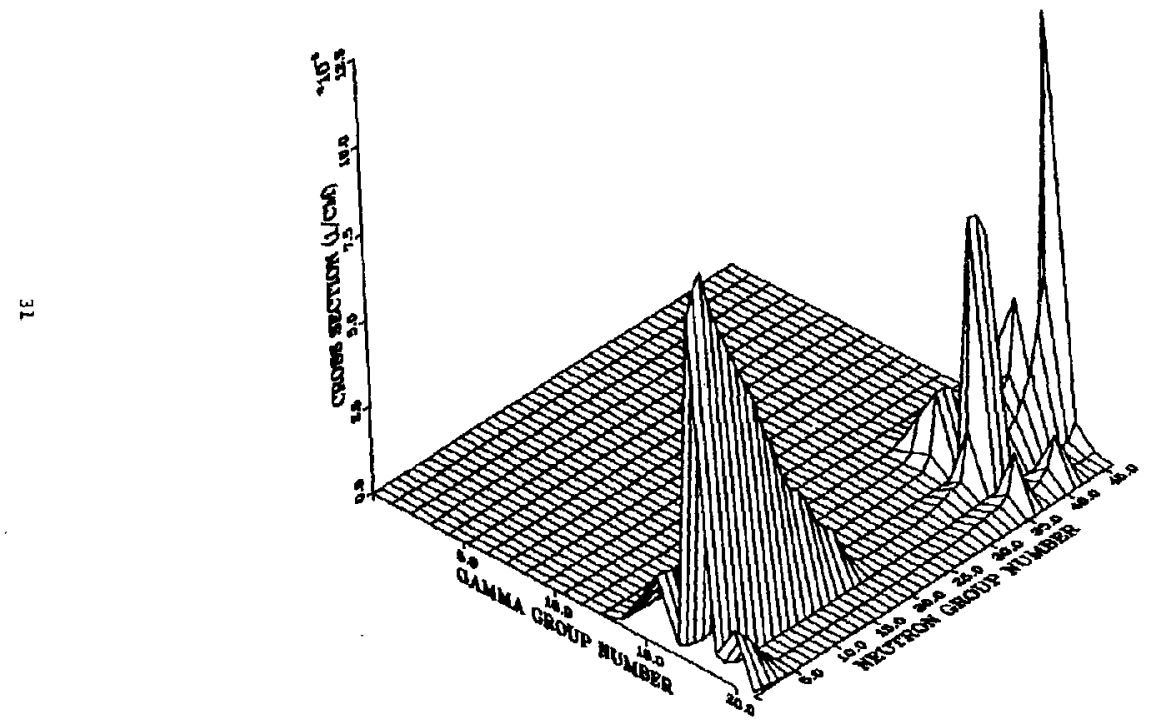

Fig. 6 


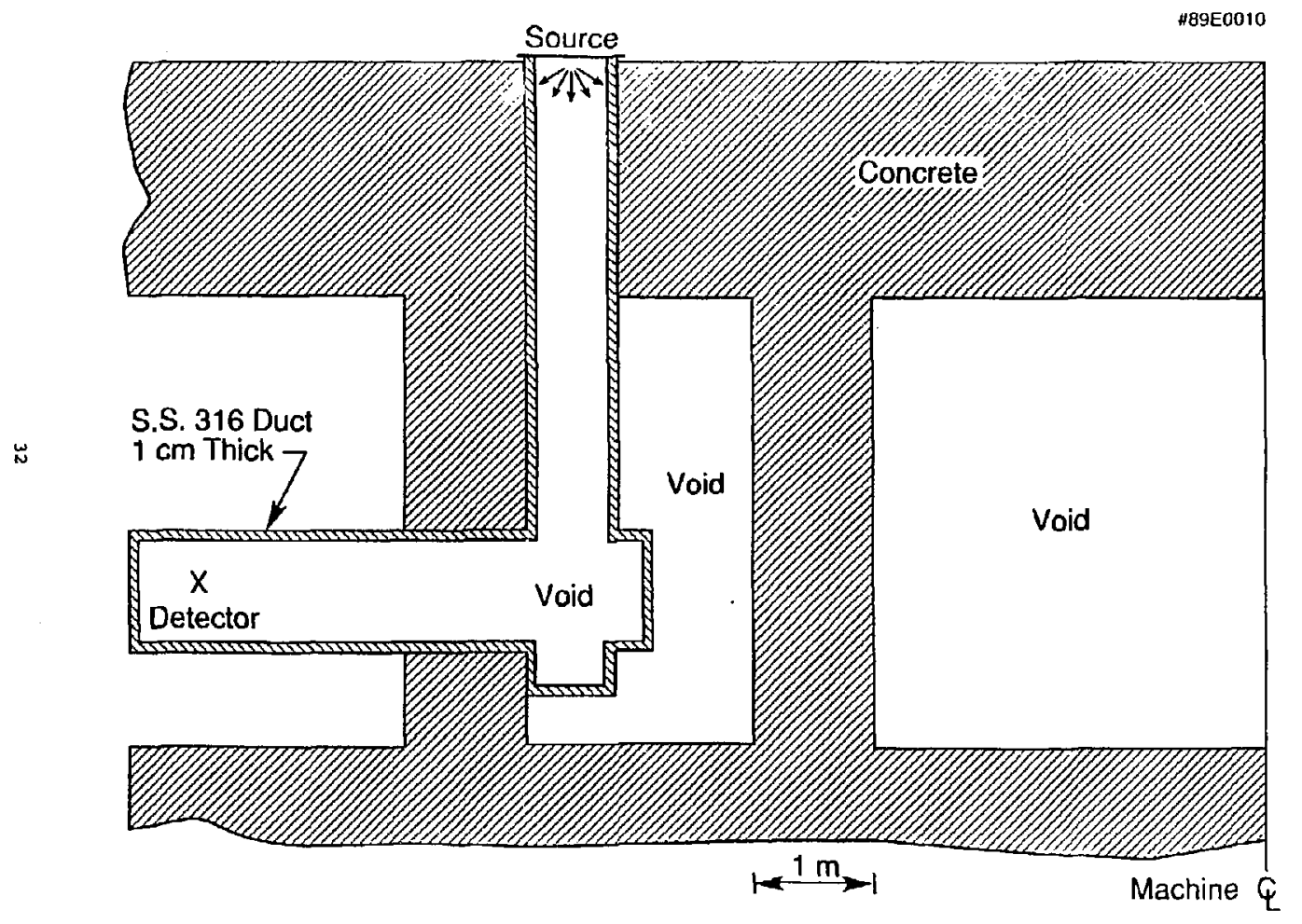

Eig. ? 


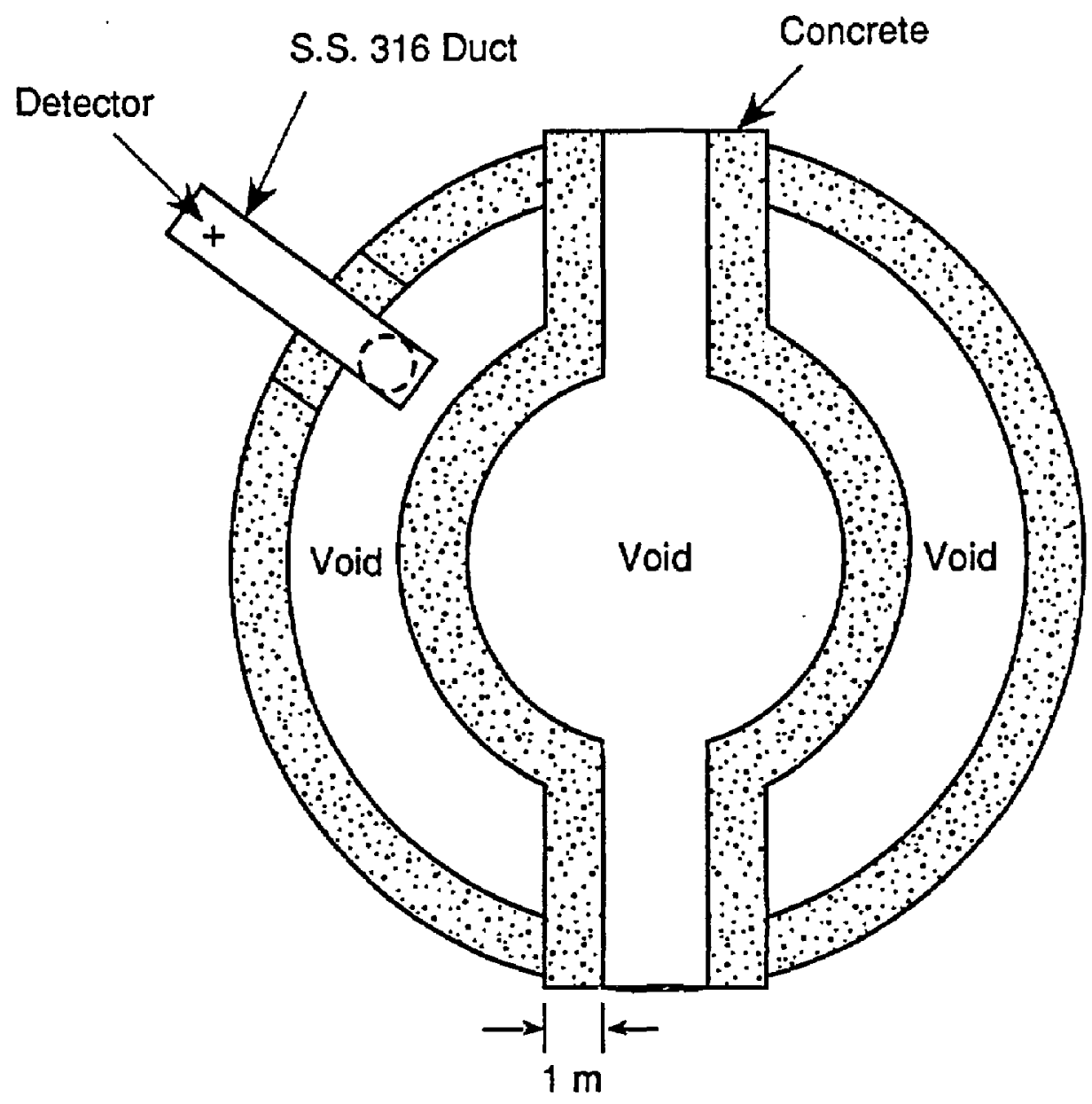

Fig. 8 


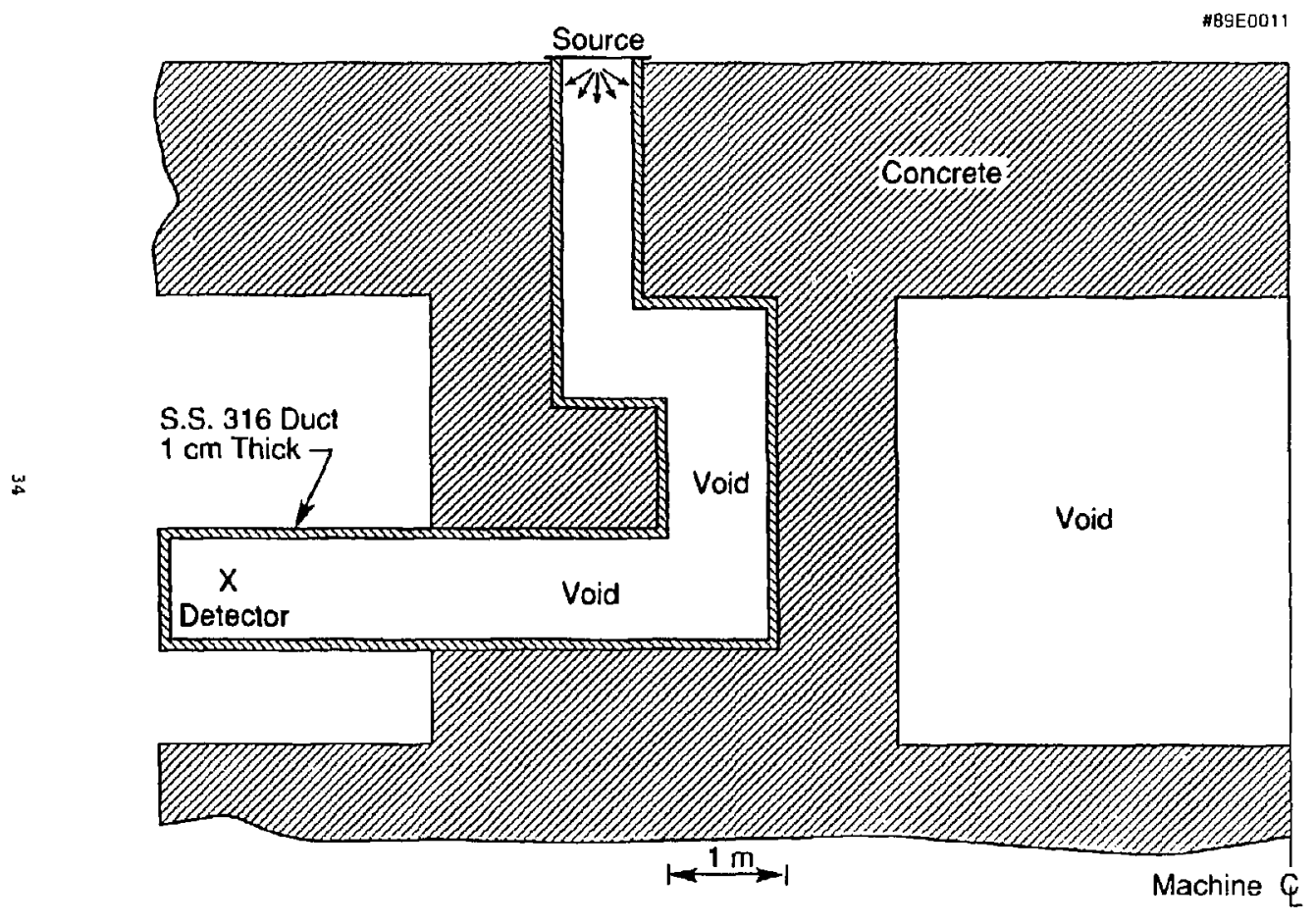

Fig. 9 
\#89E0006

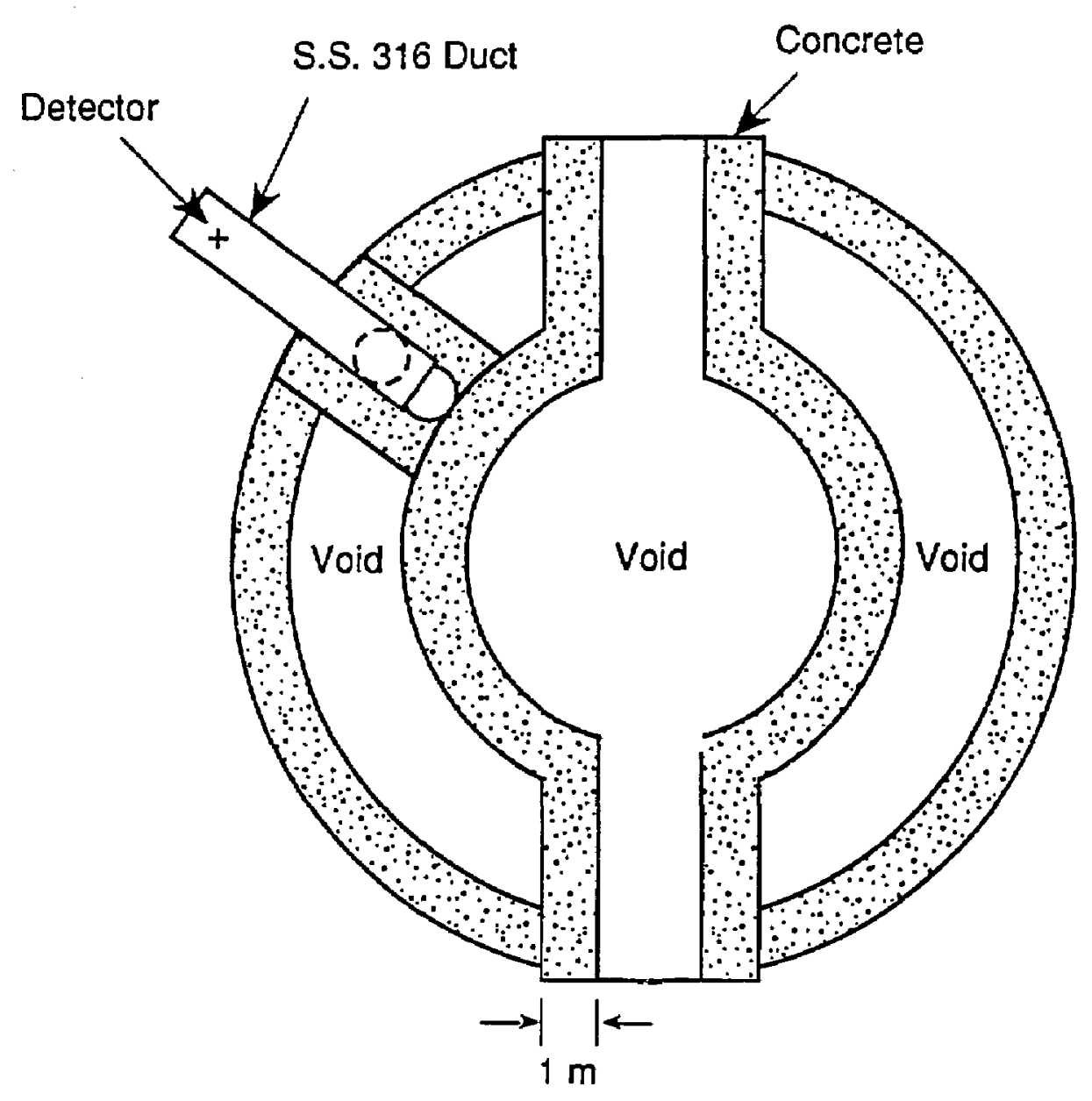

Fig. 10 


\section{REPRODULED FROM BEST AVAILABLE COPY}

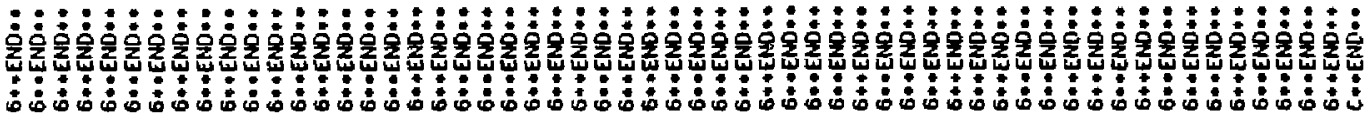

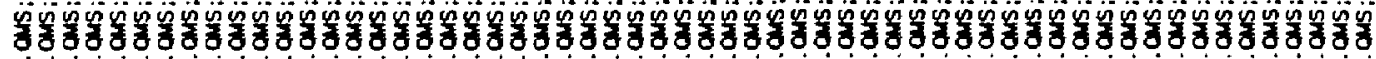

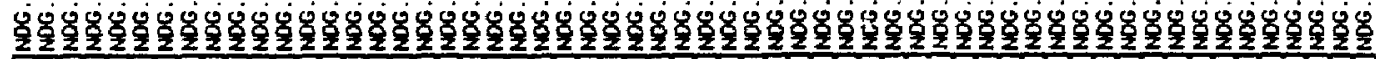

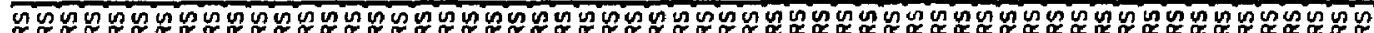

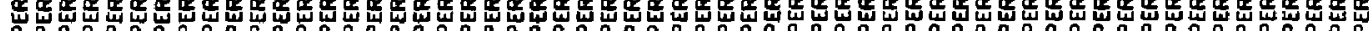

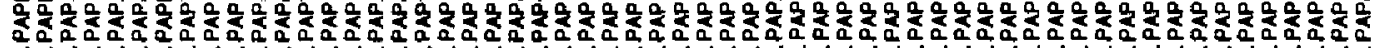

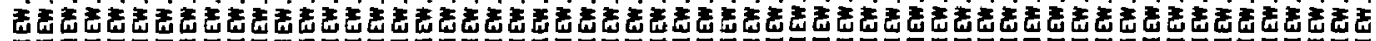

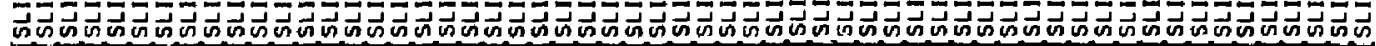

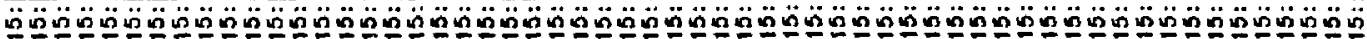

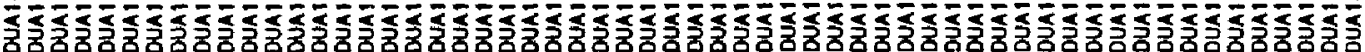

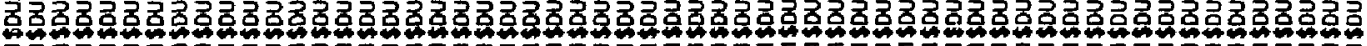
a

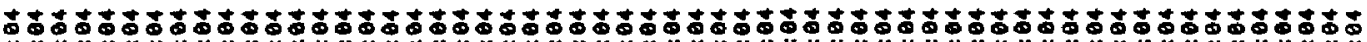

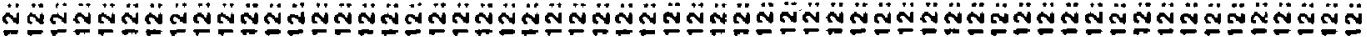

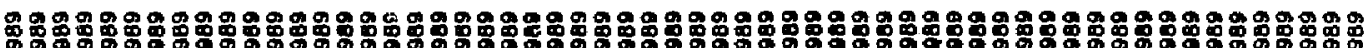

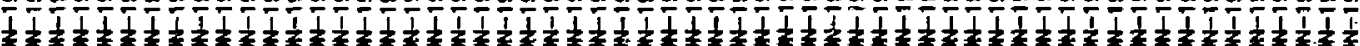

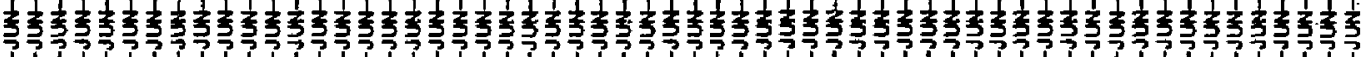
I

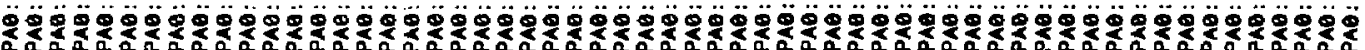

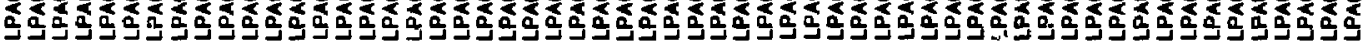

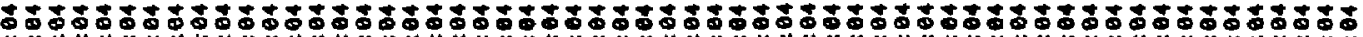

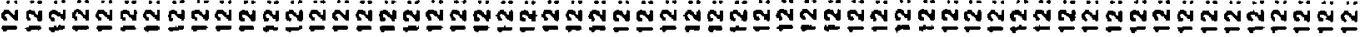

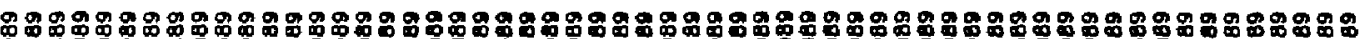

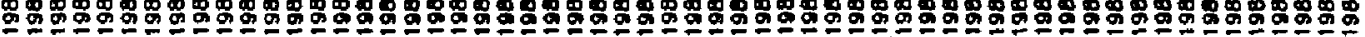

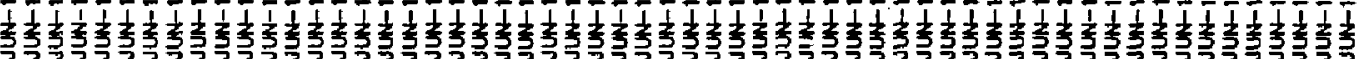

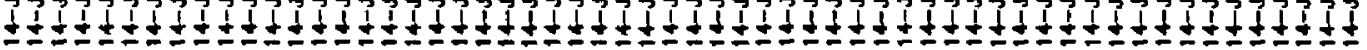

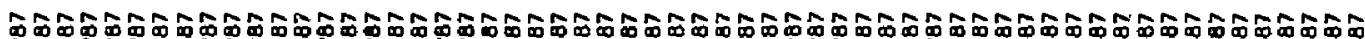

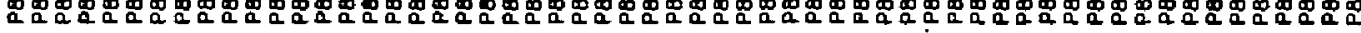

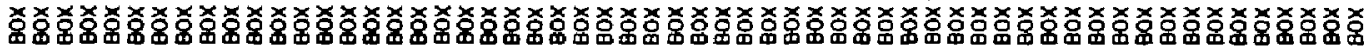

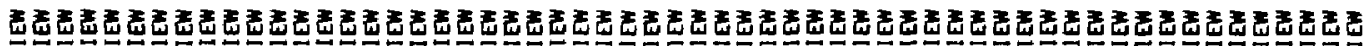

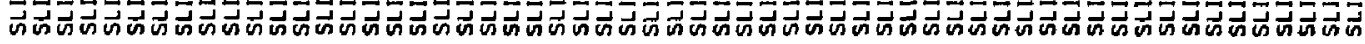

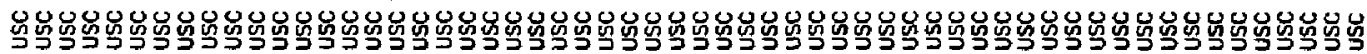

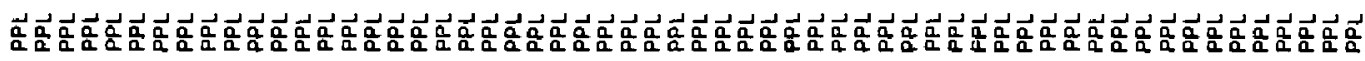


Dr. Frank J. Paolonl, Unly of Wol lengong, dustraliA Prof. M.H. Brennan, Univ Syaney, Austral IA Plasero Rasearch Lab.., Australion Nat. Unlv.., AUSTRabla Prot. I.R. Jones, FIindars Univ., AUSTRALIA Prot. F. Cab, Inst Theo Phys, AUSTRIA Prot. M. Heindlor, Instut fü Theoreplsche Physik, AUSTRIA M, Goosens, Astroncisech instituut, BeLGIUM

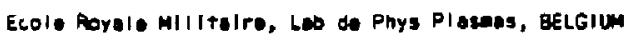
Comission-European, Do-XII fusion Prog, BelgILA Prot. R. Bowcique, RIjksuniversitelt Gent, BeLGIUw Dr. P.H. Sekanaka, Instituto fisica, ERAZil Instituto De Pesquises Especiasi-IFFe, BRAZIL Documents office, Atomis Energy of Conade Lialited, Cavaba

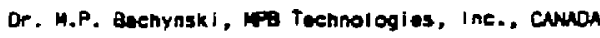
Dr. H.M. Skersgard, University of Saskatchowan, cawon Dr. H. Barnard, University of British Columbia, Cavaph Prof. t. Toichann, Univ, of Montrad, cakbn Prof, S.R. Sreantrasen, Universiry of Calgary, CawaDa Prot. Tudor W. Jehnston, Ines-Energle, cuwon Or. Bolton, Cantre canstien a fusion megnitique, cankoh Or. C.R. Jems, Univ. of Alberta, Cumba Dr. Potar Lukec, Komenskaho Univ, CZECHoslovaxiA The Litorarian, Culine Leboratory, EMSLAM The Librarian, Rutharford Applaton Layoratory, ENGLND Mrs. S,A. Hutehingon, JET Lfbrary, EMELWD C. Mouttat, Lab. de Physlque des Mllioux Ionisés, fRAnce J. Radet, Cenucronprote - Bat so6, FRunce H. C. Rinni, Liororlan, Univ, of losmina, GeEce

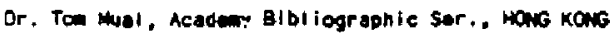
Proprint Llorary. Hungarlen acedary of Sciences, mukgafr Or, B, Das Gupta, Sahe Inst of Nucl. Phys., INDIA Or. P. Kaw, Institute for Plasere Researen, INDiA Or. Philip Alosengu, Isroel inst. of Tech, ISRAEL Librarian, Int'i Ctr Theo Phys, ITALY

Prof. 6. Rostagnl, Istltuto Gas ICrilzzati Dal OAa, I TALY Miss Clelia Da Palo, assoc ElRatom-ENEA. ITALY Dr. G. Grosso, Istituto al fisico del Plasted, ITALY Dr. H. Yanato, Toshibe Ras 8 Dav, JAPAN
Prot. I, Kowakani, Atonle Energy Ras. Ingtltute, JAPAN Prot. Kyoji Mishlkard, Univ of Hiroshima, JAPAN Direcror, OApt, Large Tokangk Ras, JAERI, JAPAH Prof. Satpanl Itoh, Krushy University, JAPAN Raseorch Into Contor, Nagoya University, JAPAN Prof. S. Tanaka, Kroto Unlversity. JAPAN Library, Kyoto University, JAPAN Prof, Nobuyuki Inouve, University of Tokyo, JAPAN S. Nor $i$, JAERI, JAPAN H. Jeong, Librarian, Koras Advanced Ënergy Ress Inst, KOREA Prof. 0.1. Choi, the Korad Adv, Inat of Sci \& Tech, XOAEA Prot. 9.5. LIley, University of Woikato, NEW ZEALANO

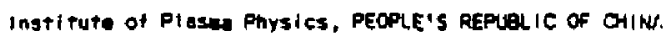
Librarian, Instltute of Phys.. PEOPL'S Repuelic of OHIMA Library. Tsing the University, PeCore's Repualic of OHIMA 2. Li, Southwat insir. Physies, PEOPLE'S REPU⿴囗IC of CHINA Prof, J.A.C. Cabral, Inat Superlor Tecnico, Portugal. Dr. Octavian Petrus, AL I CuzA University, Romania Dr. Ja de Villilers, Fualon Studies, AEC, SO africa Prot. M.A. Hallberg. University of Matal, SO AFAICh C. I.E.M.A.T., Fuaion Div. Library, SPAIN Dr. Lennart Stenflo, Univorsity of UEAA, SWEDEN Library. Aayal Institute of Teen, SWEDEM Prot. Hans Wilinelason, Chelears Univ of Tweh, SWEDEN contre Phys des Plasass, Ecol- Polytech Fad, SWITZERLAND Gibliatheak, Fon-linst yoor PI asma-fysica, THE METhERLNOS Met in Ourgut, Mldale East Technical University, TuFakey D. D.D. Ayutov, Sibortion Acad Sci. USSR Or. G.A. Eliscev, Kurchatov Institute, USSR Or. V.A. Glukhikh, Inst Electrophysical Apparatus, USSR Prat, 0,5, Padiche: Inst. of Phys. Tech, USsR Dr. L.M. Kovriztiny , institute of Gen. Physics, USSR Nucloar Ras. Estabilsheant, Julich LTC., W. GepaukY gibliothak, Inst. Fur Plasmaforschung. W. GeRauNy Dr. K. Senindler, Runr-Universitat bochun, W. GefNANY ASOEX Raading Row, elo wagner, IPPMAax-PI anck, W. GEFAaNy Librorian, Max-Planck Instlitut, W. GePany Prot. R.K. Janev, Inst of Phys, YucosLavia

\section{REPRODUCED FROM BEST AVAILABLE COPY}

